\title{
EXAMINING THE CORRELATES OF SEX OFFENDER RESIDENCE RESTRICTION VIOLATION RATES
}

\author{
Jason Rydberg \\ School of Criminology and Criminal Justice Studies \\ University of Massachusetts Lowell \\ Eric Grommon \\ School of Public and Environmental Affairs \\ Indiana University - Purdue University Indianapolis \\ Beth M. Huebner \\ Department of Criminology and Criminal Justice \\ University of Missouri - St. Louis \\ Breanne Pleggenkuhle \\ Department of Criminology and Criminal Justice \\ Southern Illinois University
}

\section{CITATION}

Rydberg, J., Grommon, E., Huebner, B. M., \& Pleggenkuhle, B. (2016). Examining the correlates of sex offender residence restriction violation rates. Journal of Quantitative Criminology. DOI: 10.1007/s10940-016-9303-z 


\title{
EXAMINING THE CORRELATES OF SEX OFFENDER RESIDENCE RESTRICTION VIOLATION RATES
}

\begin{abstract}
Objectives: This research examines the contribution of social ecological factors to the variation in sex offender residence restriction (SORR) violation rates, operationalized as a sex offender residing within a buffer zone around a school or a day care.

Methods: Drawing on data from two Midwestern states, we utilize a quasi-experimental cohortcontrol group design to examine the correlates of county-level SORR violation rates among a cohort of post-SORR sex offender parolees, and three counterfactual cohorts (pre-SORR sex offenders, pre- and post-SORR non-sex offender parolees). We model the violation rate using a series of fractional logit regressions, examining the contribution of housing market, environmental justice, and system resource variables.
\end{abstract}

Results: We observe that county-level variation in post-SORR sex offender violation rates is directly associated with concentrated disadvantage and the density of residence restrictions. The direct effect of concentrated disadvantage was unique to the post-SORR sex offender cohort. Model predictions suggest that the relationship between SORR density and concentrated disadvantage varies across the study states.

Conclusions: The results suggest that factors found to be associated with sex offender clustering (i.e., housing market characteristics) are not associated with SORR violation rates. Instead, this research suggests a model which allows for the simultaneous influence of environmental justice and system resource effects. Future research on the mechanisms underlying these effects is warranted.

Keywords: Sex Offenders; Residence Restrictions; Social Ecology; Proportional Response Models 


\section{EXAMINING THE CORRELATES OF SEX OFFENDER RESIDENCE RESTRICTION VIOLATION RATES}

In the past 20 years, sex offender residence restrictions (SORR) have been widely deployed as a means to manage the recidivism risk of sex offenders in the community (Levenson and Cotter, 2005; Meloy, Miller, and Curtis, 2008). Residence restrictions aim to impede opportunities for reoffending among known, registered sex offenders by regulating their residential proximity to areas where potential child victims congregate. This is accomplished by enacting buffer zones of varying sizes (e.g., 500 to 2,500 feet) around varying protected locations (e.g., schools, day care centers, parks, and bus stops), within which registered sex offenders are barred from holding an official residence (Meloy et al., 2008; Pacheco and Barnes, 2013; Socia, 2011). Implicitly drawing on the distance decay hypothesis (Brantingham and Brantingham, 1984), SORR are built on the assumption that sex offenders choose to locate their residences close to potential victim pools for offending purposes (Walker, Golden, and Van Houten, 2001).

However, despite wide political and popular support (Levenson, Brannon, Fortney, and Baker, 2007; Pickett, Mancini and Mears, 2013) recent research suggests that SORR are largely unsuccessful in reducing recidivism. Studies indicate that residential proximity to areas where children congregate explains little variation in reoffending among sexual offenders (Colorado Department of Public Safety, 2004; Minnesota Department of Corrections, 2003; Zandbergen, Levenson, and Hart, 2010). None of the available evaluations of residence restrictions have found that the policies result in a consistent, significant reduction in sex offense rates, both in the aggregate (Socia, 2015) and when differentiating recidivist and new offenders (Nobles, Levenson, and Youstin, 2012; Socia, 2012), or for recidivism among sex offender parolees (Huebner et al., 2014). 
Further, a large body of work has identified the negative, unintended consequences of SORR (see Levenson and Zgoba, 2014). This research demonstrates that the hypothetical or actual enactment of SORR restricts housing options for sex offenders returning from incarceration, whereas non-trivial proportions of current sex offender addresses (e.g., upwards of $50 \%$ ) would be in violation of the law and would hence be required to change residences (Barnes, Dukes, Tewksbury, and De Troye, 2009; Chajewski and Mercado, 2009; Zgoba, Levenson, and McKee, 2009). Yet, research has also examined the residential locations of sex offenders following the implementation of actual SORR policies and observed that large proportions of sex offenders were still residing at addresses that were in violation of the policy (e.g., Berensen and Applebaum, 2011; Grubesic, Mack, and Murray, 2007). The estimated violation rates vary considerably (e.g., between 30 to $90 \%$ ), and to date there is little research to account for this variation.

Given the widespread implementation of SORR (Mancini, Barnes, and Mears, 2013) in both the absence of evidence that they are effective and presence of evidence that they produce negative consequences for sex offenders (Socia, 2014a), there is a need to contextualize the implementation and enforcement of these policies, and understand non-compliance among sex offenders subject to them (Berensen and Applebaum, 2011). Using a cohort control design, we estimate a series of fractional logit models (Papke and Wooldridge, 1996) to examine countylevel variation in sex offenders' proximity to schools and daycares, and how this variation correlates with social ecology, both prior to and following the implementation of SORR. This research builds on existing work regarding the role of housing characteristics, community disorganization and criminal justice system resources in the understanding of crime and criminal justice system processes (Chamberlain and Wallace, 2015; Clear, Rose, Waring, and Scully, 
2003), particularly given that most of this work has not considered the unique position of the sex offender population. As important, we include comparable samples of non-sex offenders to understand if the changes observed are unique to the sex offender population or are part of broader correctional philosophies or system changes. Comparisons to non-sex offenders have been rare in this type of SORR research and provides a more nuanced understanding of the collateral outcomes of SORR policy.

\section{LITERATURE REVIEW}

\section{Community Housing, Economic Structure, and Prisoner Reentry}

The mechanisms that affect residential patterns among sex offenders returning from prison are similar to those that impact general offender populations. An emerging body of research on the social context of prisoner reentry suggests that inmates largely return to live in resource deprived, disadvantaged neighborhoods where they once lived (Clear, 2007; Kirk, 2009; Wallace and Papachristos, 2014). Theoretically, the social structure of a community can influence parolee outcomes in several ways. Poverty and disadvantage have been tied to the

presence and quality of institutions in the community (Sampson, Raudenbush, and Earls, 1997; Wallace, Eason, and Lindsey, 2015). Social services are not readily available in urban, disadvantaged neighborhoods, and recent research suggests that parolees who live in areas with more social service providers are less likely to recidivate (Hipp, Petersilia, and Turner, 2010). Wallace and Papachristos (2014) find support for this relationship at the zip code level using data on health care organizations and rates of new crimes and technical violations (see also Wallace, 2015). Similarly, scholars suggest that in communities with high levels of unemployment, greater disadvantage, and low social control may breed environments conducive to crime and recidivism (Drakulich, Crutchfield, Matsueda, and Rose, 2012; Wang, Mears, and Bales, 2010). 
Of particular interest to the current study is the available housing market in communities. Researchers have consistently argued that housing provides the foundation to a successful reentry transition. Much of the literature evaluating transitions from prison to the community links stable housing to decreased recidivism, improvement in employment prospects, and enhanced opportunities to build a foundation for positive social relationships (Bradley, Oliver, Richardson, and Slayter, 2001; Metraux and Culhane, 2004; Padgett et al. 2011; Yahner and Visher, 2008). Yet, returning offenders face considerable difficulties in securing stable housing due to a variety of formal and informal barriers (Nelson, Deess, and Allen, 1999; Visher and Travis, 2003). These difficulties may be exacerbated for sex offenders given that residence restrictions reduce the availability of housing opportunities (Chajewski and Mercado, 2009; Socia, 2011; Youstin and Nobles 2009; Zandbergen and Hart, 2006).

For instance, there is emerging evidence that SORR affect the context and affordability of available housing stock. Hughes and Burchfield (2008) found that that registered sex offenders were more likely to reside in socially disorganized areas (see also Clark and Duwe, 2015; Mustaine, Tewksbury, and Stengel, 2006). There is further evidence that as sex offenders moved after prison, they were increasingly more likely to reside in more disadvantaged communities (Hipp, Turner, and Janetta, 2010). In contrast, Socia (2011) found that the neighborhoods with the least amount of restricted housing tended to be significantly less disorganized than the most restricted neighborhoods. Scholarly research has highlighted a positive association between community disadvantage and failure on community supervision (Hipp et al., 2010; Kubrin and Stewart, 2006; Mears, Wang, Hay, and Bales, 2008). Less is known about if and how disadvantage may influence post-release patterns of behavior specifically for sex offenders. Although there is varying evidence on how SORR affect the quality of and context of 
available housing, there is emerging evidence that the lack of available housing leads to the clustering of sex offenders (Hughes and Kadleck, 2008; Socia, 2013; Socia, 2014b). Further, this same research notes that sex offender clustering is highest in areas of high disadvantage (see also Socia and Stamatel, 2012; Tewksbury and Mustaine, 2008). Clustering remains an important issue for the study of sex offenders given that the influx of offenders in one area can undermine informal social control and local network structures (Clear, 2007; Rose and Clear, 1998). Empirically, there is also initial evidence that in areas with concentrated parolee populations, recidivism is much higher (Chamberlin and Wallace, 2015). Stahler and colleagues (2013) argue that recidivism is not randomly distributed spatially, finding that offenders returning to areas with high levels of reincarceration are more likely to fail on parole.

\section{Non-Compliance with Sex Offender Residence Restrictions}

A SORR violation occurs when a sex offender resides at a location within a particular distance, or buffer zone around, a restricted location. Evidence consistently indicates that following SORR implementation a proportion of offenders continue to reside at addresses that are in violation of the policy (Berensen and Appelbaum, 2011; Tewksbury and Mustaine, 2006). The literature on non-compliance with SORR is currently under-developed, and researchers have posited several plausible explanations for violations. First, it is worth noting that not every sex offender identified as residing within a restriction zone should be considered in violation of the policy, as many SORR policies allow for addresses to be grandfathered (Levenson \& Hern, 2007). For legitimate violations, one explanation is that sex offenders actively and rationally choose to locate their residence close to locations with large pools of potential victims, despite supervision conditions prohibiting them from doing so (English, 1998; Walker, et al., 2001). This explanation for variation in SORR violation rates has received little empirical support. Although 
Chajewski and Mercado (2008) found that sex offenders live closer to schools or day cares than a random sample of residents, studies suggest that sex offenders are not more likely to live in areas with greater opportunities for offending (Tewksbury and Mustaine, 2008; Zgoba et al., 2009).

Alternatively, scholars have suggested that SORR significantly restructure the available housing market for sex offenders (Socia, 2011), sex offenders may continue to reside in violation due to the lack of available alternatives (Zandbergen and Hart, 2006; Zgoba, et al., 2009). Socia (2011) found that Upstate New York neighborhoods with the least amount of restricted housing tended to have fewer rental vacancies and be less affordable than the most highly restricted neighborhoods. ${ }^{i}$ Higher fair-market rent was also associated with sex offender homelessness at the county-level (see Socia, Levenson, Ackerman, and Harris, 2014). Therefore, the extent of SORR violations in an area could increase as housing becomes less available and affordable.

Using an environmental justice perspective, scholars have posited that social disorganization may influence violation rates directly through enforcement inequities (Konisky, 2009). Previous research observes that government enforcement of enacted legislation such as the Clean Air Act and Clean Water Act is significantly less frequent in counties with high levels of poverty (Konisky, 2009). Applying Black's theory of law (1976), Spina (2015) found evidence of county-level disparities in the enforcement of the Resource Conservation and Recovery Act, with socially disorganized counties receiving significantly fewer inspections. This differential enforcement has been posited to be both intentional by enforcement decision makers (Bullard and Johnson, 2000), and passive based on political resources in disadvantaged communities (Rosenstone and Hansen, 1993). Hughes and Burchfield (2008) find neighborhood disadvantage is negatively associated with sex offender distance from parks, schools, and day cares in Chicago, suggesting a stronger concentration of potential SORR violations in these 
areas. We anticipate that violation rates would be higher in more disorganized counties, as supervision agencies may be less concerned with enforcing the policy in these areas, allowing sex offenders to live within close proximity to restricted objects.

Similarly, law enforcement and community correctional agencies may not have the means to enforce residence restrictions (Berensen and Appelbaum, 2011; Grattet, Lin, and Petersilia, 2011; Lipsky, 1980; Youstin and Nobles, 2009). To the extent that criminal justice actors are responsible for locating suitable housing options for sex offenders under their supervision (Huebner et al., 2014), SORR violation rates can be expected to vary by factors such as the size and scope of the restrictions, organizational resource allocation, and caseload. Recent research has suggested that reduced caseloads improve the effectiveness of probation officer supervision (Jalbert and Rhodes, 2012), yet caseload size and turnover were found to have minimal effects on parolee technical violations (Grattet et al., 2011).

\section{Estimating the Extent of Non-Compliance with Residence Restrictions}

Estimates of non-compliance rates vary widely across studies, partially attributable to measurement techniques used. Early research using single county data denoted non-compliance rates ranging from 30\% to in excess of 90\% (Berensen and Applebaum, 2011; Grubesic et al., 2007; Tewksbury and Mustaine, 2006). The estimates must be interpreted within their proper context and inherent limitations. Researchers have created some of these measurements from public registries in one or two counties within a single state, thereby potentially harming the generalizability of the estimates. Additionally, addresses listed in registries may be incomplete or inaccurate (Berensen and Appelbaum, 2011; Grubesic et al., 2007). It is also difficult to discern if samples extracted from states' registries are subjected to retrospective application of the law or are granted grandfathering exceptions. As an alternative to registry data, recent research has 
estimated violation rates with the use of sex offenders' first address after release from prison. Statewide violation rates of $22 \%$ and $21 \%$ were respectively estimated among a two year cohort of sex offenders released from prison in Michigan and Missouri after the passage of statewide residency restriction legislation in both states (Huebner et al., 2014). Additionally, the existing literature gives little basis to determine whether these observed violation rates are distinct from sex offenders prior to the implementation of SORR or discernable from non-sex offenders. We address this shortcoming in the present study.

\section{THE CURRENT INQUIRY}

\section{Data and Methods}

\section{$\underline{\text { Study Sites }}$}

The current study examines county-level SORR violations among parolees in two Midwestern states - Michigan and Missouri. Michigan implemented residency restrictions in October, 2005. The SORR policy applied a 1,000 foot boundary around schools, and a 500 foot boundary around licensed day care centers (Michigan Sex Offender Registration Act, 2005). Missouri passed residency restrictions in June, 2006.The policy there applied a 1,000 foot boundary around both schools and licensed day care centers (Revised Statutes of Missouri, 2006). Although there is wide variation in statewide SORR laws nationally (Meloy et al., 2008;

Mancini et al., 2013), the study states are two of 13 states with boundary zones in the interval of 1,000 to $1,499 \mathrm{ft}$, which is the most common boundary interval out of the 32 states with statewide policies (Mancini et al., 2013).

Sample Generation and Geocoding

While the sex offender post-SORR violation rate is the focus of the current inquiry, four cohorts of parolees are included in the analysis: (1) pre-SORR sex offenders, (2) post-SORR sex 
offenders, (3) pre-SORR non-sex offenders, and (4) post-SORR non-sex offenders. The preSORR sex offenders provide insight into the factors correlated with sex offenders' proximity to schools and day cares prior to the implementation of SORR. The non-sex offenders allow understanding into the factors associated with parolee proximity to schools and day cares among parolees that were not subject to SORR during either period, as well as independent of sex offender status. This particular counterfactual is important given claims that sex offenders' residential patterns are qualitatively different from non-sex offenders (Walker et al., 2001) These samples were generated in several steps. Each state had implemented their SORR at different times, so the pre and post-intervention groups vary accordingly. The population of sex offenders released during the pre and post-intervention periods were included in the sample. In Michigan, pre-SORR cohorts were released from prison between January $1^{\text {st }}, 2003$ and December $31^{\text {st }}, 2005$, and the post-SORR cohorts between January $1^{\text {st }}, 2006$ and December $31^{\text {st }}$, 2007. In Missouri, the pre-SORR cohorts were released between July $1^{\text {st }}, 2004$ and June $5^{\text {th }}$, 2006, and the post-SORR cohorts were released between June $6^{\text {th }}, 2006$ and June $5^{\text {th }}, 2008$.

Next, the non-sex offender sample was selected. As the population of non-sexual offenders for this period was very large (i.e., 50,522 in Michigan and 85,785 in Missouri), propensity score techniques were used to select a matched comparison sample. Matching was based on demographic characteristics and criminal history and stratified by county urbanicity and performed separately for each state (see Huebner et al., 2013, 2014 and Appendix A for further details). This procedure produced a total overall cohort of 7,327 parolees - 1,930 Michigan sex offenders (1,502 pre-, 428 post-SORR), 1,917 Michigan non-sex offenders (1,525 pre-, 392 postSORR); 1,665 Missouri sex offenders (1,176 pre-, 489 post-SORR), and 1,815 Missouri non-sex 
offenders (1,267 pre-, 548 post-SORR), in which the sex and non-sex offenders in each state are similar on a set of observed measures (see Appendix A).

Next, ArcGIS was utilized to geocode the initial parole release address of the cohorts. Address information was obtained from the respective state Departments of Correction, and location data for schools and day cares were generated from a variety of sources (see Table 1). The current analysis focuses on the parolee's initial release address since these are the most reliably recorded. In both states the initial release address is selected during the pre-release planning process, and thus represents a product of decision making concerning the resources available to both the parolee and the parole agency (Massoglia, Firebaugh, and Warner, 2013). It is during this process that it would (ideally) be determined whether the proposed address resided within a SORR boundary zone, making the first address a salient indicator of violation rates.

The parolees' addresses were mapped using street geocoding, in which the location of a given address is determined by placing a point on the named street segment based on the address number provided (Zandbergen, 2008). Next, appropriate SORR boundaries were placed around preK-12 schools and licensed day care centers and it was determined how many cohort members in each county were residing at addresses intersecting the buffer zones. Geocoding match rates of 97.8 and $86.6 \%$ were obtained for the Michigan and Missouri cohorts, respectively. ${ }^{\mathrm{ii}}$ This process resulted in a sample of 7,327 parolees released across 198 counties in Michigan ( $\mathrm{n}=83$ counties) and Missouri $(n=115)$. It should be noted that previous research has found that street and parcel geocoding can produce different estimates of SORR violations, with street geocoding underestimating violations, and parcel geocoding generally considered to be more accurate (Zandbergen \& Hart, 2009), but has generally lower match rates than street geocoding (Zandbergen, 2008). Additionally, street geocoding provides more accurate estimates when the 
address is located within a multi-unit apartment complex (Zandbergen \& Hart, 2009), which was true for a non-trivial amount of offenders in the current inquiry. As parcel data were systematically unavailable for the counties in the current inquiry, the violation rates produced here should be considered as conservative estimates.

\section{Dependent Variables}

For each county in the data, cohort-specific SORR violation rates were calculated for use as dependent variables. The violation rate was calculated as a censored ratio variable (i.e., constrained between 0 and 1 ) as the number of cohort members residing at addresses intersecting the buffer zone divided by the total cohort members released to the county. Separate violation rates were calculated for each of the four cohorts, with the post-SORR sex offender violation rate being of primary interest, and the other three rates utilized as counterfactuals. Details on variables are included in Table 1 with descriptive statistics in Table 2. Counties are utilized as the unit of analysis in the current study for several reasons. First, as parole offices are primarily responsible for the enforcement of SORR among their supervisees, counties represent meaningful organizational units for the operation of parole in both of the study states. Second, counties are consistently used as analysis units in similar studies of governmental and criminal justice policy enforcement (Konisky, 2009; Spina, 2015; Wagenaar and Wolfson, 1995). Third, there is evidence that county characteristics (i.e., the broader political and organizational context of a community) are stronger predictors of the detection and official reactions to parolee deviance than those of smaller, community-level indicators (i.e., neighborhoods or street segments) (Morenoff and Harding, 2014). Independent Variables 
Housing market. Independent variables and their operational definitions are provided in Table 1. Previous research suggests that sex offenders are more likely to live in areas where housing is both obtainable and affordable (Socia, 2014b). As such, SORR violation rates are expected to be higher in counties with housing markets more amenable to sex offenders. Housing availability and housing affordability are included to measure characteristics of each county's housing market and are consistent with salient housing measures utilized in previous examinations of residence restrictions (Socia, 2011; Socia, et al., 2014).

Environmental justice. Policy enforcement inequities have been tied to the structural characteristics of communities, with more disadvantaged counties receiving less rigorous enforcement of environmental policies (Konisky, 2009; Spina, 2015). To examine this possibility with SORR violations, four variables were selected to represent environmental justice constructs - residential instability, racial/ethnic heterogeneity, concentrated disadvantage, and unemployment. Racial/ethnic heterogeneity was measured as a Herfindahl index utilizing five racial and ethnic groups. Following the example of Hipp and colleagues (2010), the Herfindahl index measures racial/ethnic dissimilarity (RE) in county $k$ as:

$$
R E_{k}=1-\sum_{1}^{Z=z} G_{z}^{2}
$$

Where each $z$ represents the different racial/ethnic groups present in the county, $G$ represents the proportion of the population comprised of racial/ethnic group $z$. Increasing values on the index indicate increasing levels of racial and ethnic differentiation. The other environmental justice variables are measured as oblique rotated principal components factor scores designed to represent classic social disorganization constructs (Shaw and McKay, 1942; Wilson, 1987) which have also been utilized in previous sex offender research (Hipp et al., 2010; Hughes and Burchfield, 2008; Socia, 2011). All factor scores are standardized, with higher scores indicating 
a higher degree of the measured construct. The unemployment rate was included separately as a manifest variable. iii $^{-}$

System resources. Variation in SORR violation rates may be a product of the practicality of their enforcement, and the resources available for doing so (Grattet et al., 2011). Given that initial release addresses at the study sites are decided during pre-release planning, criminal justice personnel in counties with particularly dense restrictions may have a harder time locating viable housing options for their clients. SORR density is designed to capture variation in the degree of restricted objects between counties, as the spatial distribution of schools and day cares suggests that some jurisdictions are likely to be more restricted than others (Socia, 2011). ${ }^{\text {iv }}$ The operationalization of criminal justice system resources is informed by Mears and colleagues (2008), who posited that differential exposure to law enforcement may impact recidivism during reentry. In the current inquiry, this variable is included as a proxy to capture county variation in the capacity to detect residence restriction violations, and is extracted from total county revenue, revenue devoted to law enforcement, and police density. Cohort flow represents the rate at which pre- and post-restriction cohorts were released across counties, and is operationalized as the number of parolees to given county divided by the total parolees to the state during that time period (i.e., .05 indicates that $5 \%$ of all pre-restriction parolees were released to that county). This measure captures variation in the management burden on parole offices, where higher values indicate a higher burden for county parole offices to manage in the community.

Control variables. Two variables are included as controls to account for geographic variation not captured by other ecological correlates. Urbanicity is an ordinal variable measuring the rural-urban continuum, as indicated by the US Department of Agriculture (2003). ${ }^{\mathrm{v}}$ A variable 
is also included to denote whether the county was in Missouri or Michigan (Missouri =1), accounting for unobserved static differences between counties in the two states.

Spatial dependence. Because of the inexact correspondence between county boundaries and the ecological factors which may influence SORR violation rates, it is possible that the violation rate in a given county is influenced by the features of spatially proximate counties (Kubrin and Weitzer, 2003). Global Moran's I statistics were calculated for each of the cohortspecific SORR violation rates using an inverse distance weight matrix of county centroids. These tests suggested significant spatial autocorrelation for the pre-restriction $(I=0.03, \mathrm{p}<.001)$ and post-restriction sex offender violation rates $(I=0.04, \mathrm{p}<.001)$, as well as the pre-restriction nonsex offenders $(I=0.05, \mathrm{p}<.001)$. This spatial dependence must be controlled for in multivariate modeling in order to isolate the effect of a county's characteristics on its violation rate (Socia, 2014b). A spatial lag covariate was created for the violation rate measures by averaging the respective violation rates of the 5 nearest counties, as measured by county centroids. This approach is similar to that of Mears and colleagues (2008) to account for nuisance spatial autocorrelation.

\section{[INSERT TABLE 1 ABOUT HERE - VARIABLE DESCRIPTIONS] [INSERT TABLE 2 ABOUT HERE - DESCRIPTIVE STATISTICS]}

\section{Design and Analysis Plan}

We utilize fractional logit estimation to estimate the empirical models (Papke and Wooldridge, 1996). This method was selected for several reasons. Primarily, it is well suited for modeling proportional outcome variables (i.e., constrained to between 0 and 1) (Gramig, Wolf, and Lupi, 2010). ${ }^{\mathrm{vi}}$ Additionally, the predictions from the fractional logit method have been demonstrated to have greater interpretability and statistical power than the arcsine square root transformation for use with more traditional linear models (Warton and Hui, 2011). 
The fractional logit model takes the conditional mean assumption,

$$
E\left(y_{i} \mid \mathrm{x}_{i}\right)=G\left(\mathrm{x}_{i} \beta\right)=e^{x \beta} /\left(1+e^{x \beta}\right)
$$

where $G($.$) is the cumulative distribution function of the logistic distribution, y$ represents the residence restriction violation rate in county $i, \mathrm{x}$ is a vector of covariates, and $\beta$ a vector of coefficients (Gramig et al., 2010; Papke and Wooldridge, 1996). The fractional logit is a quasimaximum likelihood method using the Bernoulli log-likelihood function,

$$
L L(\beta)=y_{i} \log \left[G\left(\mathrm{x}_{i} \beta\right)\right]+\left(1-y_{i}\right) \log \left[1-G\left(x_{i} \beta\right)\right]
$$

Under the conditional mean assumption in Equation 3, this log-likelihood function is identical to that of binary logit regression (Gramig et al., 2010; Papke and Wooldridge, 1996). The use of this model ensures that predicted values from the model will fall within an appropriate unit interval. Computationally, the models are estimated through a binomial generalized linear model with a logit link function, utilizing the continuous violation rate as the outcome variable and weighting the model by the number of cohort members released to the county. In this sense, the estimation is presented in the form of a weighted logit regression. ${ }^{\text {vii }}$ Importantly, this procedure gives counties with more parolees larger weights, ensuring that counties with small numbers of

parolees do not unduly influence the results. Consistent with the recommendations of Papke and Wooldridge (1996), the $\mathrm{R}^{2}$ utilized is the normal $\mathrm{R}^{2}$, calculated as squared correlation between the predicted and observed violation rates. All analyses were performed using the R statistical computing environment (R Core Team, 2015).

\section{RESULTS}

\section{Violation Rates and Descriptive Statistics}

Estimated aggregate SORR violation rates and confidence intervals are displayed in Table 2. Overall, approximately one quarter (24\%) of the initial release addresses intersected a 
residence restriction buffer. The violation rate for Missouri was higher than in Michigan. These estimated rates are generally lower than those produced by previous studies (Berensen and Applebaum, 2011; Grubesic et al., 2007; Tewksbury and Mustaine, 2006). In comparing the other cohorts, sex offenders during the pre-restriction period resided in proximity to schools and day care centers at a similar rate to the post-restriction period, and non-sex offenders demonstrated higher violation rates in both periods.

With the goal of explaining variation in violation rates across counties, county-level descriptive statistics are displayed in Table 3 . There were 82 counties $(41.4 \%)$ with a postrestriction violation rate of $0 \%$, and $5(2.5 \%)$ with a violation rate of $100 \%{ }^{\text {viii }}$

\section{[TABLE 3 ABOUT HERE]}

\section{Factors Contributing to Violation Rates}

The next set of tables display the results of the fractional logit models regressing violation rates on county covariates. ${ }^{\text {ix }}$ Table 4 presents the model for the sex offender post-SORR violation rates (Model 2), and Models 1, 3, and 4 display violation rates for the three counterfactual cohorts included in the analysis. ${ }^{x}$ Across all of the full conditional models, Model 2 provides the most adequate fit and explains a relatively large proportion of variation in SORR violation rates. ${ }^{\mathrm{xi}}$ This is an important observation as this model provides estimates concerning SORR violation rate correlates for the cohort actually subject to the legislation. The results suggest positive and significant associations between concentrated disadvantage, SORR density, Missouri counties, and SORR violation rates.

Differences between estimates for sex offenders and non-sex offenders, and between preand post-restriction cohorts were conducted by pooling violation rates across cohorts and then interacting a post-SORR indicator with every model covariate (Williams, 2009). ${ }^{\text {xii }}$ Bolded 
coefficients indicate that the estimates for the sex offenders and non-sex offenders are significantly different for that restriction period (i.e., comparing pre-restriction sex offenders to pre-restriction non-sex offenders; post-restriction sex offenders to post-restriction non-sex offenders) (see Appendix C for full results). Comparing post-restriction sex offenders to postrestriction non-sex offenders, the estimated effects for unemployment and concentrated disadvantage are significantly different between the two cohorts (Models 2 and 4). There were several differences between the pre-restriction and post-restriction sex offender cohorts as well. Criminal justice system resources and cohort flow were positively associated with sex offender violation rates for the pre-restriction (Model 1), but not the post-restriction cohort (Model 2). Concentrated disadvantage was only positively associated with violation rates for post-restriction sex offenders. Restriction density and the Missouri indicator were the only consistent predictors of violation rates across all cohorts, and housing market factors were not associated with violation rates for any cohort. It is important to note that inclusion of the spatial lag did not change any substantive conclusions from the models.

\section{[TABLE 4 ABOUT HERE]}

\section{$\underline{\text { Response Surfaces }}$}

The results of the fractional logit estimation suggests that there are three factors associated with sex offender post-SORR violation rates across counties - concentrated disadvantage, restriction density, and the state in which counties were located. To understand how these factors interact to produce variation in violation rates, predicted response surfaces were estimated. These response surfaces apply the fractional logit model estimated in Model 2 (Table 4), but include a three-way interaction between concentrated disadvantage, restriction density, and Missouri. A simulated dataset is produced from this model by varying the values of 
concentrated disadvantage and restriction density from their minimum to their maximum across each of the values of one another, replicated within Michigan and Missouri, while other covariates are fixed at their mean. ${ }^{\text {xii }}$ In other words, these graphics enable a visual depiction of how SORR violation rates are predicted to vary across the entire range of restriction density and concentrated disadvantage, all else being equal.

Figure 1 displays the estimated response surfaces, with separate predictions for Michigan and Missouri. Across the two states, the association between concentrated disadvantage and SORR density on SORR violation rates varied considerably. Consistent with previous literature on SORR and the residential patterns of sex offenders (Hughes and Burchfield, 2008; Socia, 2011), violation rates in both states are predicted to be highest when restriction density is high and disadvantage low, and when disadvantage is high and restriction density low. However, in Michigan, violation rates were highest among counties with either high concentrated disadvantage or high SORR density, but not both. The highest rates of violation were found in counties with a combination of high concentrated disadvantage and low SORR density ( $\sim 56 \%)$ and were followed by counties with low concentrated disadvantage and high SORR density ( 28\%). In Missouri, a multiplicative effect was apparent. SORR violation rates were highest when county concentrated disadvantage was high and SORR density was large $(\sim 55 \%)$. High rates of violation were found in counties with a combination of low concentrated disadvantage and high SORR density ( $\sim 66 \%)$ and were followed by counties with high concentrated disadvantage and low SORR density $(\sim 35 \%)$.

\section{[INSERT FIGURE 1 HERE - PREDICTED RESPONSE SURFACES]}

\section{$\underline{\text { Supplemental Analysis - Patterns of Cohort Release }}$}

The research design allows the possibility that the correlates of violation rates may be due 
to changes in release patterns to counties before and after SORR implementation. A system resource variable - cohort flow - was entered into the fractional logit regression equations to examine how paroles patterns across counties effects violation rates net all other measures. As an additional check to insure that the results were not simply a function of the flow of cohort samples to Michigan and Missouri counties following SORR legislation, Poisson regression models of sex offender and non-sex offenders released to each county on county-level variables were estimated (see Table 5).

Overall, the results did not provide any evidence to suggest significant changes in release patterns to counties after the enactment of SORR. Both pre- and post-SORR, sex offenders were more likely to be released to counties with dense restrictions, and less likely to be released to counties with more affordable housing. As such, it is unlikely that differential patterns of release for pre- and post-SORR sex offenders and non-sex offenders into Michigan and Missouri counties influenced the results. This notion of parolees returning to similar areas has been observed in other research using smaller units of analysis (see Rey et al., 2014).

\section{[TABLE 5 ABOUT HERE] \\ SUMMARY AND DISCUSSION}

Despite the widespread implementation of SORR in jurisdictions across the United States, research suggests that considerable proportions of sex offenders continue to reside at addresses in violation of state laws and policies (Berensen and Applebaum, 2011). This research sought to examine the correlates of variation in SORR violation rates among matched parolees across counties in two Midwestern States with statewide residence restriction laws. Three potentially complementary perspectives informed the measures chosen for this purpose housing market characteristics, environmental justice, and system resources. Consistent with 
previous findings from Hughes and Burchfield (2008), the analyses suggest that, controlling for a host of relevant factors including SORR density, counties with relatively high levels of concentrated disadvantage had more sex offenders maintaining an address in violation of SORR legislation. The positive effect of concentrated disadvantage is unique to post-restriction sex offenders, and was not observed amongst pre-restriction sex offender or non-sex offenders.

As expected, the density of restricted objects also contributed to higher estimated SORR violation rates across counties, and Missouri counties tended to have higher SORR violation rates than Michigan counties. These effects were observed across all cohorts and were not directly attributable to sex offenders subject to SORR legislation. Predicted response surfaces were estimated to further dissect how these stable effects may have interacted with concentrated disadvantage to affect post-restriction sex offenders (see Figure 1). The results presented different effect profiles for each state, but confirmed that Michigan and Missouri counties with less concentrated disadvantage and low SORR density had lower predicted SORR violation rates. Although these counties tended to have smaller violation rates on average, the predicted violation rate of $5 \%$ indicates that a low baseline level of violation rather than a null violation rate is to be expected. This finding contextualizes previous research suggesting high baseline violation rates (e.g., Berensen and Applebaum, 2011; Youstin and Nobles, 2009), indicating that estimated rates may be a product of the specific communities examined (i.e., high restriction density and concentrated disadvantage). Relatively lower rates would be expected in nearby communities without such features.

\section{Limitations}

Several limitations merit discussion. First, street geocoding was utilized to determine whether the cohort members' release addresses were in violation of the SORR policy, yet 
research indicates that parcel geocoding produces more accurate estimates of SORR violations (Zandbergen and Hart, 2009). Parcel data were not available for the current inquiry, increasing the likelihood that we underestimate the rate of SORR violations (Zandbergen and Hart, 2009). However, street geocoding has been found to be more accurate than parcel geocoding when the offender's address falls in a multi-unit apartment complex (Zandbergen, Levenson, and Hart, 2010), which was the case for a sizable proportion of the post-release sex offender cohort. In all, the violation rates presented in this study must be interpreted as conservative estimates.

Second, this research is only capable of examining the correlates of SORR violation rates, and does not suggest whether the observed associations are causal in nature. For instance, Grattet and colleagues (2011) suggest that variation in SORR violations will reflect the capacity to implement SORR and may be a function of resources available to criminal justice agencies and the tolerance of criminal justice actors to deviance. Indeed, the willingness of parole agents to implement and enforce SORR can be tied to their personal support for the policy (Payne, Tewksbury, and Mustaine, 2013). In an ideal scenario, it would be possible to discriminate between variation in violation rates due to enforcement inequities and discretion due to resource availability. Unfortunately, we were only able to utilize proxy measures for SORR supervision regimes in the current analysis, which are focused on differential resources for implementing and enforcing SORR (e.g., criminal justice system resources and cohort flow).

Additionally, the findings of this research must be interpreted relative to the states and counties sampled. The external validity of the conclusions is aided by these states employing the most common size and scope of SORR (Mancini et al., 2013). However, descriptive and multivariate results identified differences between Michigan and Missouri counties. Michigan counties tended to have less available and affordable housing, residential instability and 
concentrated disadvantage, as well as higher unemployment, racial/ethnic heterogeneity, SORR densities, and criminal justice system resources relative to Missouri. Violation rates among Michigan counties for post-restriction sex offenders were 52\% lower than Missouri counties. While a dummy variable was used to attempt to control for observable and unobservable differences between counties in the states, selection bias cannot be completely ruled out. Future research on SORR violation rates must make effort to detail pre-existing differences in the unit of analysis and determine how such differences influence estimated SORR violation rates.

Finally, this research sought to enhance conclusions regarding the correlates of SORR violation rates by including comparable cohorts of non-sex offenders. The non-sex offender sample was derived via a propensity score matching procedure as part of a larger evaluation of SORR in the study states (see Huebner et al., 2014). The sample derivation was not without limitations, as a reliance on administrative and official data for matching allows for the possibility that differences observed between sex and non-sex offenders are sensitive to omitted variable biases (See Appendix A; Loughran, Wilson, Nagin, \& Piquero, 2015). We cannot completely rule out this possibility nor the potential for over- or underestimate effects affiliated with matching model dependence. However, we were able to take advantage of using a two-state design to compare SORR violations between sex and non-sex offenders within each state, producing similar results. There is no baseline from which to compare these results and determine if observed differences are consistent such biases. Future replications integrating new advancements in matching techniques can inform and build on the robustness of these findings.

\section{Conclusions}

Two primary results can be deduced from this research. First, county-level variation in SORR violation rates is largely shaped by concentrated disadvantage and its independence from 
or coupling with SORR density. Although direct effects for both measures were observed in full conditional models, the effect concentrated disadvantage appears to be the key correlate driving SORR violation rates for post-restriction sex offenders. In Missouri, SORR density is a critical factor and more so in the presence of concentrated disadvantage. The mechanisms underlying this interaction remain unclear. For instance, a positive association for concentrated disadvantage is consistent with both active mechanisms akin to enforcement inequities (Spina, 2015), and passive mechanisms affiliated with typical sex offender housing patterns (Hughes and Burchfield, 2008). Similarly, the positive association with concentrated disadvantaged suggests that the highest violation rates can be found in communities with the lowest capacity for informal social control (Sampson et al., 1997). However, the lack of an association between concentrated disadvantage and SORR violations for the pre-SORR sex offender cohort suggests that it matters in a way following the implementation of SORR that it did not before. The lack of a clear mechanism for this finding highlights the complexity of the operation of SORR, which individual community corrections and law enforcement organizations must interpret and implement in the context of individual and organizational goals (Lipsky, 1980; McCleary, 1978). Ethnographic research into the operation of SORR will help explicate these associations, particularly in light of the lack of research suggesting that SORR are effective in reducing recidivism (Huebner et al., 2014; Socia, 2014a).

Second, many of the social ecological indicators predicted to explain SORR violation rate variation had minimal effects for the post-restriction sex offender cohort. Housing availability, residential instability, criminal justice resources, and urbanity were positively associated with SORR violation rates in preliminary iterative conditional models (available upon request, see note xi). However, the direct effects of these indicators were moderated in the full conditional 
models (Table 4). The remaining housing market, environmental justice, and system resource indicators were all unrelated to SORR violation rates. These findings offer important context to the concentrated disadvantage and SORR density results. Specifically, factors which have been noted to be associated with sex offender concentration (see Clark and Duwe, 2015; Socia, 2014b; Tewksbury and Mustaine, 2008) were unrelated to sex offender proximity to schools and day cares in the current research. Additionally, the amount of criminal justice resources available in a county to enforce SORR laws and manage cohorts of individuals released from prison does not directly shape post-SORR violation rates. Rather than being a function of housing markets and/or enforcement capacity, SORR violation rates appear to be a function of how counties are environmentally structured. This implication is important in the context of research suggesting the salience of social ecology in the recidivism of returning offenders (Chamberlain and Wallace, 2015). As returning sex offenders may be at a higher risk of recidivism on account of being released to disadvantaged areas (Hipp et al., 2010), these same sex offenders may be especially vulnerable to technical supervision revocation on account of SORR violations.

As this was the first study to examine variation in SORR violation rates across geographic units, future replications are needed to confirm and extend the primary findings. To do so will require the integration of criminal justice system resource theoretical perspectives and indicators. As knowledge on how SORR influences or is influenced by housing characteristics and community disorganization continues to grow, the role of system resources lags behind. Not only does this perspective make the most conceptual sense for why SORR violation rates would be observed, the preliminary evidence from this study suggests that the use of a resource perspective in tandem with housing characteristics and community disorganization frameworks may downplay the association between housing markets and SORR violations. 


\section{REFERENCES}

Barnes, J. C., Dukes, T., Tewksbury, R., and De Troye, T. M. (2009). Analyzing the impact of a statewide residence restriction law on South Carolina sex offenders. Criminal Justice Policy Review, 20(1), 21-43.

Berenson, J. A., and Appelbaum, P. S. (2011). A geospatial analysis of the impact of sex offender residency restrictions in two New York counties. Law and Human Behavior, $35(3), 235-246$.

Black, D. (1976). The behavior of law. New York: Academic Press.

Bradley, K. H., Oliver, R. B., Richardson, N. C., and Slayter, E. M. (2001). No place like home: Housing and the ex-prisoner. Issue brief. Boston: Community Resources for Justice.

Brantingham, P. J., and Brantingham, P. L. (1984). Environmental Criminology. Prospect Heights, IL: Waveland Press.

Bullard, R. D., and Johnson, G. S. (2000). Environmentalism and public policy: Environmental justice: Grassroots activism and its impact on public policy decision making. Journal of Social Issues, 56(3), 555-578.

Chajewski, M., and Mercado, C. C. (2009). An evaluation of sex offender residency restriction functioning in town, county, and city-wide jurisdictions. Criminal Justice Policy Review, 20(1), 44-61.

Chamberlain, A. W., and Wallace, D. (2015). Mass reentry, neighborhood context and recidivism: Examining how the distribution of parolees within and across neighborhoods impacts recidivism. Justice Quarterly, advance online publication. doi: 10.1080/07418825.2015.1012095

Clark, V. A, and Duwe, G. (2015). What predicts where sex offenders live? An examination of census tract data in Minnesota. Criminal Justice Policy Review, advance online publication. doi: 10.1177/0887403415594200

Clear, T. R. (2007). Imprisoning communities: How mass incarceration makes disadvantaged neighborhoods worse. New York: Oxford University Press.

Clear, T. R., Rose, D. R., Waring, E., and Scully, K. (2003). Coercive mobility and crime: A preliminary examination of concentrated incarceration and social disorganization. Justice Quarterly, 20(1), 33-64.

Colorado Department of Public Safety. (2004). Report on safety issues raised by living arrangements for and location of sex offenders in the community. Denver, CO: Sex Offender Management Board. 
Drakulich, K., Crutchfield, R., Matsueda, R., and Rose, K. (2012). Instability, informal control, and criminogenic situations: community effects of returning prisoners. Crime, Law and Social Change, 57(5), 493-519.

English, K. (1998). The containment approach: An aggressive strategy for the community management of adult sex offenders. Psychology, Public Policy, and Law, 4(1-2), 218.

Ferrari, S., and Cribari-Neto, F. (2004). Beta regression for modelling rates and proportions. Journal of Applied Statistics, 31(7), 799-815.

Gramig, B. M., Wolf, C. A., and Lupi, F. (2010). Understanding adoption of livestock health management practices: The case of bovine leukosis virus. Canadian Journal of Agricultural Economics, 58(3), 343-360.

Grattet, R., Lin, J., and Petersilia, J. (2011). Supervision regimes, risk, and official reactions to parolee deviance. Criminology, 49(2), 371-399.

Grubesic, T. H., Mack, E., and Murray, A. T. (2007). Geographic exclusion: Spatial analysis for evaluating the implications of Megan's Law. Social Science Computer Review, 25(2), $143-162$.

Hipp, J. R., Petersilia, J., and Turner, S. (2010). Parolee recidivism in california: the effect of neighborhood context and social service agency characteristics. Criminology, 48(4), 947979.

Hipp, J. R., Turner, S., and Jannetta, J. (2010). Are sex offenders moving into social disorganization? Analyzing the residential mobility of California parolees. Journal of Research in Crime and Delinquency, 47(4), 558-590.

Huebner, B. M., Bynum, T. S., Rydberg, J., Kras, K., Grommon, E., and Pleggenkuhle, B. (2013). An evaluation of sex offender residency restrictions in Michigan and Missouri. Report submitted to the National Institute of Justice.

Huebner, B. M., Kras, K. R., Rydberg, J., Bynum, T. S., Grommon, E., and Pleggenkuhle, B. (2014). The effect and implications of sex offender residence restrictions: Evidence from a two-state evaluation. Criminology and Public Policy, 13(1), 139-168.

Hughes, L. A., and Burchfield, K. B. (2008). Sex offender residence restrictions in Chicago: An environmental injustice? Justice Quarterly, 25(4), 647-673.

Hughes, L. A., and Kadleck, C. (2008). Sex offender community notification and community stratification. Justice Quarterly, 25(3), 469-495.

Jalbert, S. K., and Rhodes, W. (2012). Reduced caseloads improve probation outcomes. Journal of Crime and Justice, 35(2), 221-238. 
Kirk, D. S. (2009). A natural experiment on residential change and recidivism: Lessons from Hurricane Katrina. American Sociological Review, 74(3), 484-505.

Konisky, D. M. (2009). Inequities in enforcement? Environmental justice and government performance. Journal of Policy Analysis and Management, 28(1), 102-121.

Kubrin, C. E., and Stewart, E. A. (2006). Predicting who reoffends: The neglected role of neighborhood context in recidivism studies. Criminology, 44(1), 165-197.

Kubrin, C. E. and Weizer, R. (2003). New directions in social disorganization theory. Journal of Research in Crime and Delinquency, 40(4), 374-402.

Levenson, J. S., Brannon, Y. N., Fortney, T., and Baker, J. (2007). Public perceptions about sex offenders and community protection policies. Analysis of Social Issues and Public Policy, $7(1), 137-161$.

Levenson, J. S., and Cotter, L. P. (2005). The impact of sex offender residence restrictions: 1,000 feet from danger or one step from absurd? International Journal of Offender Therapy and Comparative Criminology, 49(2), 168-178.

Levenson, J. S., \& Hern, A. L. (2007). Sex offender residence restrictions: Unintended consequences and community reentry. Justice Research and Policy, 9(1), 59-73.

Levenson, J. S., and Zgoba, K. M. (2014). Sex offender residence restrictions: The law of unintended consequences. In R. G. Wright (ed.) Sex offender laws: Failed policies, new directions. New York, NY: Springer (pp. 180-189).

Lipsky, M. (1980). Street-level bureaucracy: Dilemmas of the individual in public service. Russell Sage Foundation.

Loughran, T. A., Wilson, T., Nagin, D. S., \& Piquero, A. R. (2015). Evolutionary regression? Assessing the problem of hidden biases in criminal justice applications using propensity scores. Journal of Experimental Criminology, 11(4), 631-652.

Mancini, C., Barnes, J. C., and Mears, D. P. (2013). It varies from state to state: An examination of sex crime laws nationally. Criminal Justice Policy Review, 24(2), 166-198.

Massoglia, M., Firebaugh, G., and Warner, C. (2013). Racial variation in the effect of incarceration on neighborhood attainment. American Sociological Review, 78(1), $142-$ 165.

McCleary, R. (1978). Dangerous men: The sociology of parole. Thousand Oaks: Sage.

Mears, D. P., Wang, X., Hay, C., and Bales, W. D. (2008). Social ecology and recidivism: Implications for prisoner reentry. Criminology, 46(2), 301-340. 
Meloy, M. L., Miller, S. L., and Curtis, K. M. (2008). Making sense out of nonsense: The deconstruction of state-level sex offender residence restrictions. American Journal of Criminal Justice, 33(2), 209-222.

Metraux, S., and Culhane, D. P. (2004). Homeless shelter use and reincarceration following prison release. Criminology and Public Policy, 3(2), 139-160.

Minnesota Department of Corrections. (2003). Level three sex offenders residential placement issues. St Paul: Author.

Morenoff, J. D., and Harding, D. J. (2014). Incarceration, prisoner reentry, and communities. Annual Review of Sociology, 40, 411-429.

Mustaine, E. E., Tewksbury, R., and Stengel, K. M. (2006). Social disorganization and residential locations of registered sex offenders: Is this a collateral consequence? Deviant Behavior, 27(3), 329-350.

Nobles, M. R., Levenson, J. S., and Youstin, T. J. (2012). Effectiveness of residence restrictions in preventing sex offense recidivism. Crime and Delinquency, 58(4), 491-513.

Nelson, M., Deess, P., and Allen, C. (1999). The first month out: Post-incarceration experiences in New York City. New York: Vera Institute of Justice.

Pacheco, D., and Barnes, J. C. (2013). Sex offender residence restrictions: A systematic review of the literature. In K. Harrison and B. Rainey (eds.) The Wiley-Blackwell Handbook of Legal and Ethical Aspects of Sex Offender Treatment and Management (pp. 424-444). Hoboken, NJ: John Wiley and Sons.

Padgett, D. K., Stanhope, V., Henwood, B. F., and Stefancic, A. (2011). Substance use outcomes among homeless clients with serious mental illness: Comparing housing first with treatment first programs. Community Mental Health Journal, 47(2), 227-232.

Papke, L. E., and Wooldridge, J. (1996). Econometric methods for fractional response variables with an application to $401(\mathrm{k})$ plan participation rates. Journal of Applied Econometrics, $11,619-632$.

Payne, B. K., Tewksbury, R., and Mustaine, E. E. (2013). Identifying the sources of community corrections professionals' attitudes about sex offender residence restrictions: The impact of demographics and perceptions. Crime and Delinquency, advance online publication. doi: $10.1177 / 0011128712470993$

Pickett, J. T., Mancini, C., and Mears, D. P. (2013). Vulnerable victims, monstrous offenders, and unmanageable risk: Explaining public opinion on the social control of sex crime. Criminology, 51(3), 729-759. 
R Core Team. (2015). R: A language and environment for statistical computing. R Foundation for Statistical Computing, Vienna, Austria.

Rey, S. J., Murray, A. T., Grubesic, T. H., Mack, E., Wei, R., Anselin, L., and Griffin, M. (2014). Sex offender residential movement patterns: A Markov Chain analysis. The Professional Geographer, 66(1), 102-111.

Rose, D. R., and Clear, T. R. (1998). Incarceration, social capital, and crime: implications for social disorganization theory. Criminology, 36(3), 441-480.

Rosenstone, S., and Hansen, J. M. (1993). Mobilization, participation and democracy in America. New York: Macmillan.

Sampson, R. J., Raudenbush, S. W., and Earls, F. (1997). Neighborhoods and violent crime: A multilevel study of collective efficacy. Science, 277(5328), 918-924.

Shaw, C. R., and McKay, H. D. (1942). Juvenile delinquency and urban areas. Chicago: University of Chicago Press.

Socia, K. M. (2011). The policy implications of residence restrictions on sex offender housing in Upstate NY. Criminology and Public Policy, 10(2), 351-389.

Socia, K. M. (2012). The efficacy of county-level sex offender residence restrictions in New York. Crime and Delinquency, 58(4), 612-642.

Socia, K. M. (2013). Residence restrictions and the association with registered sex offender clustering. Criminal Justice Policy Review, 24(4), 441-472.

Socia, K. M. (2014). Residence Restrictions Are Ineffective, Inefficient, and Inadequate: So Now What? Criminology and Public Policy, 13(1), 179-188.

Socia, K. M. (2014). Examining the Concentration of Registered Sex Offenders in Upstate New York Census Tracts. Crime and Delinquency, advance online publication. doi: $10.1177 / 0011128714526563$

Socia, K. M. (2015). State residence restrictions and forcible rape rates: A multistate quasiexperimental analysis of UCR data. Sexual Abuse: A Journal of Research and Treatment, 27(2), 205-227.

Socia, K. M., Levenson, J. S., Ackerman, A. R., and Harris, A. J. (2014). "Brothers under the bridge": Factors influencing the transience of registered sex offenders in Florida. Sexual Abuse: A Journal of Research and Treatment, advance online publication. doi: 10.1177/1079063214521472.

Socia, K. M., and Stamatel, J. P. (2012). Neighborhood characteristics and the social control of registered sex offenders. Crime and Delinquency, 58(4), 565-587. 
Spina, F. (2015). Environmental justice and patterns of state inspections. Social Science Quarterly, 96(2), 417-429.

Stahler, G. J., Mennis, J., Belenko, S., Welsh, W. N., Hiller, M. L., and Zajac, G. (2013). Predicting recidivism for released state prison offenders: Examining the influence of individual and neighborhood characteristics and spatial contagion on the likelihood of reincarceration. Criminal Justice and Behavior, 40(6), 690-711.

Tewksbury, R., and Mustaine, E. E. (2006). Where to find sex offenders: An examination of residential locations and neighborhood conditions. Criminal Justice Studies, 19(1), 61-75.

Tewksbury, R., and Mustaine, E. E. (2008). Where registered sex offenders live: Community characteristics and proximity to possible victims. Victims and Offenders, 3(1), 86-98.

Visher, C. A., and Travis, J. (2003). Transitions from prison to community: Understanding individual pathways. Annual Review of Sociology, 89-113.

Wagenaar, A. C., and Wolfson, M. (1995). Deterring sales and provision of alcohol to minors: a study of enforcement in 295 counties in four states. Public Health Reports, 110(4), 419.

Walker, J. T., Golden, J. W., and VanHouten, A. C. (2001). The geographic link between sex offenders and potential victims: A routine activities approach. Justice Research and Policy, 3(2), 15-33.

Wallace, D. (2015). Do neighborhood organizational resources impact recidivism? Sociological Inquiry, 85(2), 285-308. doi: 10.1111/soin.12072

Wallace, D., Eason, J. M., and Lindsey, A. M. (2015). The influence of incarceration and reentry on the availability of health care organizations in Arkansas. Health and Justice, 3(1), 111.

Wallace, D., and Papachristos, A. V. (2014). Recidivism and the availability of health care organizations. Justice Quarterly, 31(3), 588-608.

Wang, X. I. A., Mears, D. P., and Bales, W. D. (2010). Race-specific employment contexts and recidivism. Criminology, 48(4), 1171-1211.

Warton, D. I., and Hui, F. K. (2011). The arcsine is asinine: The analysis of proportions in ecology. Ecology, 92(1), 3-10.

Williams, R. (2009). Using heterogeneous choice models to compare logit and probit coefficients across groups. Sociological Methods \& Research, 37(4), 531-559.

Wilson, W. J. (1987). The truly disadvantaged: The inner city, the underclass, and public policy. University of Chicago Press. 
Wooldridge, J. M. (2010). Econometric analysis of cross section and panel data. Cambridge: MIT press.

Yahner, J, and Visher, C. (2008). Illinois prisoners' reentry success three years after release. Washington, DC: Urban Institute.

Youstin, T. J., and Nobles, M. R. (2009). Residency restrictions: A geospatial analysis of sex offender movement over time. Crime Mapping: A Journal of Research and Practice, 1, $55-76$.

Zandbergen, P. A. (2008). A comparison of address point, parcel and street geocoding techniques. Computers, Environment and Urban Systems, 32(3), 214-232.

Zandbergen, P. A., and Hart, T. C. (2006). Reducing housing options for convicted sex offenders: Investigating the impact of residency restriction laws using GIS. Justice Research and Policy, 8(2), 1-24.

Zandbergen, P. A., and Hart, T. C. (2009). Geocoding accuracy considerations in determining residency restrictions for sex offenders. Criminal Justice Policy Review, 20(1), 62-90.

Zandbergen, Paul A., Levenson, J. S., and Hart, T. C. (2010). Residential proximity to schools and daycares: An empirical analysis of sex offense recidivism. Criminal Justice and Behavior, 37(5), 482-502.

Zgoba, K. M., Levenson, J., and McKee, T. (2009). Examining the impact of sex offender residence restrictions on housing availability. Criminal Justice Policy Review, 20(1), 91110.

\section{Statutes Cited}

Michigan Sex Offenders Registration Act, Public Act 121 of 2005 (2005).

Revised Statutes of Missouri, Chapter 589 Sections 400 to 425 and 43.650, RSMo (2006). 
Table 1. Description of Measures Available

\begin{tabular}{|c|c|c|}
\hline Variable & Description & Source \\
\hline $\begin{array}{l}\text { SORR Violation } \\
\text { Rate }\end{array}$ & $\begin{array}{l}\text { Proportion of sample member's first } \\
\text { addresses in violation of SORR buffer zone } \\
\text { divided by total sample members in that } \\
\text { county. }\end{array}$ & $\begin{array}{l}\text { Michigan/Missouri } \\
\text { Departments of } \\
\text { Corrections }\end{array}$ \\
\hline SORR Density & $\begin{array}{l}\text { Total number of schools and daycares for } \\
\text { every } 1,000 \text { residents. }\end{array}$ & $\begin{array}{l}\text { Michigan Department } \\
\text { of Information } \\
\text { Technology; Michigan } \\
\text { Center for Educational } \\
\text { Performance and } \\
\text { Information; Missouri } \\
\text { State Police; Missouri } \\
\text { Statistical Analysis } \\
\text { Center }\end{array}$ \\
\hline Housing Availability & $\begin{array}{l}\text { Proportion of vacant housing units that are } \\
\text { for rent. }\end{array}$ & U.S. Census (2000) \\
\hline $\begin{array}{l}\text { Housing } \\
\text { Affordability }\end{array}$ & $\begin{array}{l}\text { Fair market rent for a one-bedroom } \\
\text { apartment divided by median contract rent. }\end{array}$ & $\begin{array}{l}\text { U.S. Census (2000); } \\
\text { H.U.D. }(2000)\end{array}$ \\
\hline Unemployment Rate & Percent unemployed residents & U.S. Census (2000) \\
\hline $\begin{array}{l}\text { Residential } \\
\text { Instability } \\
\alpha=.79\end{array}$ & $\begin{array}{l}\text { Factor score extracted from } \% \text { of households } \\
\text { living elsewhere in the previous } 5 \text { years }\left(\alpha_{-j}=\right. \\
.71), \% \text { renter occupied units }\left(\alpha_{-j}=.65\right) \text {, and } \\
\% \text { multi-dwelling units }\left(\alpha_{-j}=.78\right) \text {. }\end{array}$ & U.S. Census (2000) \\
\hline $\begin{array}{l}\text { Racial/Ethnic } \\
\text { Heterogeneity }\end{array}$ & $\begin{array}{l}\text { Herfindahl index of American Indian, Asian, } \\
\text { Black, Hispanic, and White residents. }\end{array}$ & U.S. Census (2000) \\
\hline $\begin{array}{l}\text { Concentrated } \\
\text { Disadvantage } \\
\alpha=.85\end{array}$ & $\begin{array}{l}\text { Factor score extracted from } \% \text { poverty }\left(\alpha_{-\mathrm{j}}=\right. \\
.76) \text {, median household income }\left(\alpha_{-\mathrm{j}}=.81\right), \% \\
\text { residents receiving supplemental security } \\
\text { income }\left(\alpha_{-\mathrm{j}}=.75\right), \% \text { residents over } 25 \text { with } \\
\text { no HS diploma }\left(\alpha_{-\mathrm{j}}=.79\right) \text {, and } \% \text { of female } \\
\text { headed households with children }\left(\alpha_{-\mathrm{j}}=.92\right) \text {. }\end{array}$ & U.S. Census (2000) \\
\hline $\begin{array}{l}\text { Criminal Justice } \\
\text { System Resources } \\
\alpha=.65\end{array}$ & $\begin{array}{l}\text { Factor score extracted from total county } \\
\text { revenue per capita }\left(\alpha_{-j}=.61\right) \text {, police } \\
\text { expenditures per capita }\left(\alpha_{-j}=.49\right) \text {, and police } \\
\text { density }\left(\alpha_{-j}=.56\right) \text {. }\end{array}$ & $\begin{array}{l}\text { U.S. Census (2000); } \\
\text { Uniform Crime Reports } \\
(2000)\end{array}$ \\
\hline Cohort Flow & $\begin{array}{l}\text { Proportion of total pre- and post-restriction } \\
\text { cohorts released to the county }\end{array}$ & $\begin{array}{l}\text { Produced from current } \\
\text { data }\end{array}$ \\
\hline Urbanicity & $\begin{array}{l}\text { Urban rural continuum code, ranging from } \\
1=\text { most rural to } 9=\text { most urban. }\end{array}$ & USDA (2003) \\
\hline
\end{tabular}

Note: $\alpha=$ Cronbach's alpha; $\alpha_{-\mathrm{j}}=$ Cronbach's alpha if item removed. 
Table 2. Descriptive Statistics for Michigan and Missouri Counties $(\mathbf{N}=198)$

\begin{tabular}{lcccc}
\hline Variable & $\begin{array}{c}\text { All Counties } \\
(\mathrm{N}=198)\end{array}$ & $\begin{array}{c}\text { Michigan } \\
(\mathrm{N}=83)\end{array}$ & $\begin{array}{c}\text { Missouri } \\
(\mathrm{N}=115)\end{array}$ & $\begin{array}{l}\text { Test Statistic } \\
(\mathrm{df})\end{array}$ \\
\hline $\begin{array}{l}\mathrm{M}(\mathrm{SD}) / \% \\
\text { SORR Violation Rate }\end{array}$ & $0.20(0.23)$ & $0.14(0.19)$ & $0.24(0.24)$ & $t(171)=3.16^{* * *}$ \\
SO - Pre-Restriction & $0.17(0.24)$ & $0.10(0.14)$ & $0.21(0.28)$ & $t(140)=3.35^{* * *}$ \\
SO - Post-Restriction & $0.21(0.23)$ & $0.14(0.17)$ & $0.26(0.26)$ & $t(170)=3.93^{* * *}$ \\
NSO - Pre-Restriction & $0.22(0.30)$ & $0.19(0.30)$ & $0.24(0.30)$ & $t(103)=1.10$ \\
NSO - Post-Restriction & & & & \\
Housing Market & $0.18(0.13)$ & $0.12(0.12)$ & $0.21(0.12)$ & $t(174)=5.33^{* * *}$ \\
Housing Availability & $1.49(0.47)$ & $1.29(0.41)$ & $1.63(0.46)$ & $t(188)=5.49^{* * *}$ \\
Housing Affordability & & & & \\
Environmental Justice & $0.06(0.02)$ & $0.07(0.02)$ & $0.05(0.02)$ & $t(139)=5.24 * * *$ \\
Unemployment Rate & $0.00(0.91)$ & $-0.30(0.88)$ & $0.22(0.87)$ & $t(175)=4.15^{* * *}$ \\
Residential Instability & $0.12(0.10)$ & $0.14(0.11)$ & $0.10(0.09)$ & $t(155)=2.59^{*}$ \\
Racial/Ethnic Het. & $0.00(0.97)$ & $-0.44(0.61)$ & $0.32(1.06)$ & $t(188)=6.35^{* * *}$ \\
Conc. Disadvantage & & & & \\
System Resources & $1.85(0.59)$ & $2.19(0.54)$ & $1.60(0.49)$ & $t(168)=7.94 * * *$ \\
SORR Density & $0.00(0.82)$ & $0.32(0.71)$ & $-0.23(0.82)$ & $t(190)=4.98^{* * *}$ \\
CJ System Resources & $0.01(0.03)$ & $0.01(0.03)$ & $0.01(0.02)$ & $t(113)=0.84$ \\
Pre-Rest. Cohort Flow & $0.01(0.03)$ & $0.01(0.03)$ & $0.01(0.02)$ & $t(117)=0.84$ \\
Post-Rest. Cohort Flow & & & & \\
Controls & $4.50(2.71)$ & $4.66(2.58)$ & $4.38(2.80)$ & $t(185)=0.73$ \\
Urbanicity & $58.08 \%$ & -- & -- & - \\
Missouri & & & &
\end{tabular}

$* \mathrm{p}<.05 ; * * \mathrm{p}<.01 ; * * * \mathrm{p}<.001$

Note: $\mathrm{SO}=$ Sex Offender; NSO = Non-Sex Offender; SORR = Sex Offender Residence Restriction. 
Table 3. Aggregate Cohort Violation Rates

\begin{tabular}{lccc}
\hline Cohort Period & Both States & Michigan & Missouri \\
& $\bar{x}(\mathrm{SE})[95 \% \mathrm{CI}]$ & $\bar{x}(\mathrm{SE})[95 \% \mathrm{CI}]$ & $\bar{x}(\mathrm{SE})[95 \% \mathrm{CI}]$ \\
\hline Sex Offenders & & & \\
Pre-Restrictions & $0.23(0.01)$ & $0.19(0.01)$ & $0.27(0.01)$ \\
& {$[0.21-0.24]$} & {$[0.17-0.21]$} & {$[0.25-0.30]$} \\
Post-Restrictions & $0.24(0.01)$ & $0.18(0.02)$ & $0.28(0.02)$ \\
& {$[0.21-0.27]$} & {$[0.15-0.22]$} & {$[0.25-0.33]$} \\
Non-Sex Offenders & & & \\
Pre-Restrictions & $0.27(0.01)$ & $0.23(0.01)$ & $0.32(0.01)$ \\
& {$[0.25-0.29]$} & {$[0.21-0.25]$} & {$[0.29-0.34]$} \\
Post-Restrictions & $0.27(0.01)$ & $0.19(0.02)$ & $0.32(0.02)$ \\
& {$[0.24-0.30]$} & {$[0.16-0.24]$} & {$[0.28-0.36]$} \\
\hline
\end{tabular}

Note: Confidence intervals are estimated as Wilson Score Intervals. 
Table 4. Fractional Logit Regression Models of SORR Violation Rates on County-Level Variables $(\mathbf{N}=198)$

\begin{tabular}{|c|c|c|c|c|}
\hline & \multicolumn{2}{|c|}{ Sex Offenders } & \multicolumn{2}{|c|}{ Non-Sex Offenders } \\
\hline & Model 1 & Model 2 & Model 3 & Model 4 \\
\hline Violation Rate $\rightarrow$ & Pre-Restriction & $\begin{array}{c}\text { Post- } \\
\text { Restriction }\end{array}$ & Pre-Restriction & $\begin{array}{c}\text { Post- } \\
\text { Restriction }\end{array}$ \\
\hline $\begin{array}{l}\text { Independent } \\
\text { Variables }\end{array}$ & Est. (SE) & Est. (SE) & Est. (SE) & Est. (SE) \\
\hline Housing Market & & & & \\
\hline Housing Availability ${ }^{\mathrm{a}}$ & $0.09(0.10)$ & $0.09(0.18)$ & $0.18(0.10)$ & $0.08(0.18)$ \\
\hline Housing Affordability & $-0.32(0.27)$ & $-0.73(0.48)$ & $0.04(0.26)$ & $0.10(0.44)$ \\
\hline Environmental Justice & & & & \\
\hline Unemployment Rate $^{\mathrm{b}}$ & $-0.30(0.17)$ & $-0.63(0.33)$ & $0.16(0.15)$ & $0.64(0.25) *$ \\
\hline Residential Instability & $-0.09(0.10)$ & $0.23(0.15)$ & $-0.01(0.09)$ & $-0.08(0.16)$ \\
\hline Racial/Ethnic Het. ${ }^{\mathrm{b}}$ & $-0.06(0.14)$ & $0.26(0.21)$ & $0.12(0.13)$ & $0.05(0.21)$ \\
\hline Conc. Disadvantage & $0.14(0.08)$ & $0.38(0.13) * *$ & $-0.01(0.08)$ & $-0.05(0.13)$ \\
\hline System Resources & & & & \\
\hline SORR Density & $0.68(0.16)^{* * *}$ & $0.59(0.24)^{*}$ & $0.47(0.15)^{* *}$ & $0.55(0.23)^{*}$ \\
\hline CJ System Resources & $0.25(0.07)^{* * *}$ & $-0.04(0.12)$ & $0.29(0.07)^{* * *}$ & $0.26(0.12)^{*}$ \\
\hline Cohort Flow $^{\mathrm{b}}$ & $0.21(0.10)^{*}$ & $0.08(0.14)$ & $0.01(0.10)$ & $0.19(0.14)$ \\
\hline Controls & & & & \\
\hline Urbanicity & $0.00(0.04)$ & $0.04(0.07)$ & $-0.02(0.04)$ & $-0.09(0.07)$ \\
\hline Missouri & $0.97(0.16)^{* * *}$ & $0.79(0.27)^{* *}$ & $0.68(0.16)^{* * *}$ & $1.14(0.25)^{* * *}$ \\
\hline Spatial Lag & $0.05(0.61)$ & $0.60(0.77)$ & $1.29(0.50)^{* *}$ & $-0.46(0.73)$ \\
\hline Intercept & $-3.30(0.81)^{* * *}$ & $-4.17(1.38)^{* * *}$ & $-2.13(0.75) * * *$ & $0.33(1.22)$ \\
\hline $\mathrm{n}$ & 173 & 150 & 174 & 138 \\
\hline Log Likelihood & -256.59 & -132.46 & -247.07 & -140.92 \\
\hline Model $\chi^{2}$ & $151.35 * * *$ & $81.71 * * *$ & $199.23 * * *$ & $71.52 * * *$ \\
\hline Normal $\mathrm{R}^{2}$ & 0.09 & 0.34 & 0.20 & 0.10 \\
\hline RESET ( $p$ value) & $1.67(0.08)$ & $1.71(0.08)$ & $1.27(0.24)$ & $1.38(0.19)$ \\
\hline
\end{tabular}

Note: $* \mathrm{p}<.05 ; * * \mathrm{p}<.01 ; * * * \mathrm{p}<.001$; Bolded values indicate that estimated coefficient is significantly different $(\mathrm{p}<.05)$ between sex offender and non-sex offender violation rates for that restriction period (see Appendix C).

${ }^{a}$ Indicates that the predictor has been standardized.

${ }^{\mathrm{b}}$ Indicates that the predictor has been logged. 
Table 5. Poisson Regression of Sex Offender and Non-Sex Offender Cohort Flow on County-Level Variables $(\mathrm{N}=198)$

\begin{tabular}{|c|c|c|c|c|}
\hline & \multicolumn{2}{|c|}{ Sex Offenders } & \multicolumn{2}{|c|}{ Non-Sex Offenders } \\
\hline & Model 5 & Model 6 & Model 7 & Model 8 \\
\hline Independent Variables & $\begin{array}{c}\text { Pre-Restriction } \\
\text { Est. (SE) }\end{array}$ & $\begin{array}{c}\text { Post- } \\
\text { Restriction } \\
\text { Est. (SE) } \\
\end{array}$ & $\begin{array}{c}\text { Pre-Restriction } \\
\text { Est. (SE) }\end{array}$ & $\begin{array}{c}\text { Post- } \\
\text { Restriction } \\
\text { Est. (SE) }\end{array}$ \\
\hline Housing Market & & & & \\
\hline Housing Availability $^{\mathrm{a}}$ & $0.00(0.04)$ & $0.04(0.07)$ & $0.02(0.04)$ & $0.07(0.07)$ \\
\hline Housing Affordability ${ }^{\mathrm{b}}$ & $-0.30(0.11)^{* *}$ & $-0.41(0.18)^{*}$ & $0.21(0.11)^{*}$ & $0.17(0.17)$ \\
\hline Environmental Justice & & & & \\
\hline Unemployment Rate $^{\mathrm{b}}$ & $-0.00(0.06)$ & $0.12(0.10)$ & $0.05(0.06)$ & $-0.04(0.11)$ \\
\hline Residential Instability & $-0.01(0.04)$ & $0.01(0.06)$ & $0.03(0.04)$ & $0.04(0.06)$ \\
\hline Racial/Ethnic Het. & $-0.02(0.05)$ & $-0.03(0.08)$ & $0.04(0.05)$ & $0.04(0.08)$ \\
\hline Conc. Disadvantage & $0.01(0.03)$ & $0.04(0.05)$ & $0.01(0.03)$ & $0.02(0.05)$ \\
\hline System Resources & & & & \\
\hline SORR Density & $0.24(0.05)^{* * *}$ & $0.23(0.08)^{* *}$ & $-0.26(0.05)^{* * *}$ & $-0.30(0.09)^{* *}$ \\
\hline CJ System Resources & $-0.04(0.03)$ & $-0.08(0.05)$ & $0.01(0.03)$ & $0.00(0.05)$ \\
\hline Controls & & & & \\
\hline Urbanity & $0.03(0.02)^{*}$ & $0.02(0.02)$ & $0.00(0.02)$ & $0.06(0.03)^{*}$ \\
\hline Missouri & $0.11(0.06)$ & $0.03(0.02)$ & $-0.12(0.06)$ & $-0.03(0.10)$ \\
\hline Intercept & $-1.36(0.27)^{* * *}$ & $-0.97(0.44)^{*}$ & $-0.13(0.28)$ & $-0.89(0.50)$ \\
\hline AIC & 843.29 & 612.03 & 833.96 & 559.25 \\
\hline Model $\chi^{2}$ & $51.68 * * *$ & $24.40 * *$ & $75.74 * * *$ & $82.50 * * *$ \\
\hline Dispersion p-value & 0.99 & 1.00 & 0.99 & 1.00 \\
\hline
\end{tabular}

Note: $* \mathrm{p}<.05 ; * * \mathrm{p}<.01 ; * * * \mathrm{p}<.001 ;$ Logarithm of total sex offenders and non-sex offenders released into that county during the restriction period (pre- or post-) is used as the exposure.

${ }^{a}$ Indicates that the predictor has been standardized.

${ }^{\mathrm{b}}$ Indicates that the predictor has been logged. 
Figure 1. Response Surface - Predicted Post-Restriction SORR Violation Rate across Restriction Density and Concentrated Disadvantage

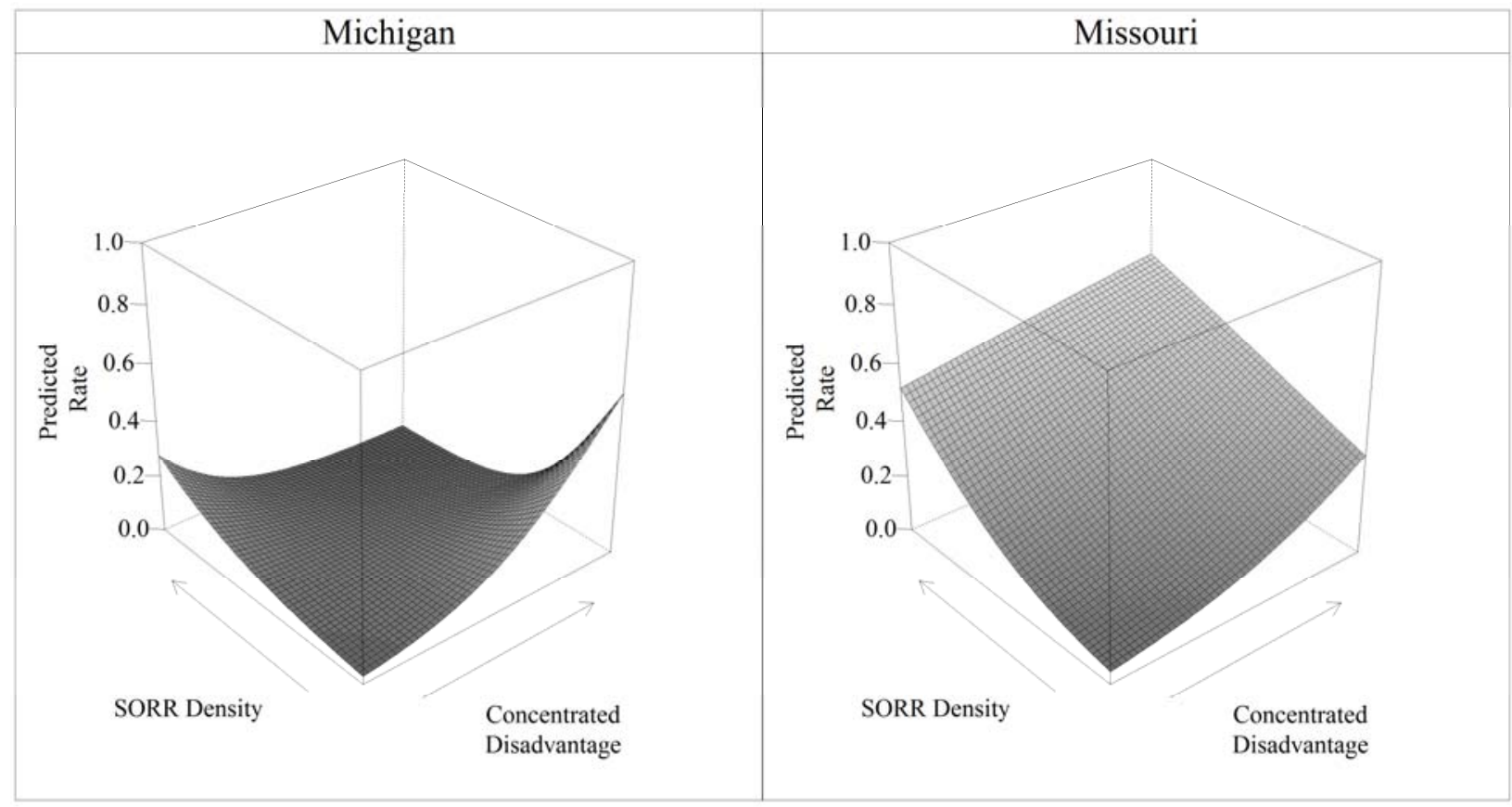




\section{EXAMINING THE CORRELATES OF SEX OFFENDER RESIDENCE RESTRICTION VIOLATION RATES}

\section{APPENDICES}

\section{Appendix A: Data Reduction via Propensity Score Matching}

This appendix describes the use of propensity score matching as a data reduction strategy in the current inquiry and addresses concerns with its use. The data utilized in this manuscript were gleaned from a larger evaluation of sex offender residence restrictions (SORR) in Michigan and Missouri (Huebner et al., 2014). The primary purpose of this broader evaluation was to examine the impact of SORR on recidivism for comparable samples of sex and non-sex offender parolees. In order to isolate the effects of residence restrictions on recidivism we sought to select a comparable sample of non-sex offenders. Because the pool of potential non-sex offender comparisons released during the study periods were quite large (with 50,522 in Michigan and 85,785 in Missouri) and heterogeneous, we utilized an informed approach to data reduction to secure non-sex offender samples that were similar to the sex offenders prior to requesting address and outcome data. Specifically, propensity score matching was utilized to match non-sex offenders to the sex offender parolees in each state. Because certain factors affect both selection to sex offender status as well as the probability of recidivism, group imbalance in these factors potentially confounds estimates of sex offender status on potential correctional outcomes (Morgan and Harding, 2006; Rosenbaum and Rubin, 1983). In this sense, the explicit goal was to model selection to sex offender status in order to produce groups whose outcomes will not be contingent upon sex offender status. The following section outlines the utilization of propensity score matching towards this goal. 


\section{Propensity Score Specification}

Propensity score matching is an important tool, but by no means serves as a solution to all selection bias problems associated with quasi-experimental research designs (Apel and Sweeten, 2010). While the utility of propensity score matching was advanced in the early 1980 s (Rosenbaum and Rubin, 1983) there remains much debate and ambiguity about the best practices to equate pretreatment covariates among treatment and comparison groups (Apel and Sweeten, 2010; Stuart, 2010). Propensity score matching is the simplest and most widely used strategy (King and Nelson, 2016) and is most appropriate for research where there are high levels of observable imbalance exist between treatment statuses (King and Nielsen, 2016; King et al., 2011), where many pretreatment covariates are used to estimate the initial scalar score (equal to or more than 20) (Gu and Rsoenbaum, 1993), and when large sample sizes remain after the matching process has been employed (King and Nielsen, 2016; King et al., 2011).

Critics of this strategy have suggested that it produces a propensity score paradox; an unintended consequence of creating more imbalances occurs as matches continue to be generated and unmatched units are discarded (King and Nielsen, 2016; King et al., 2011). Although the ability to achieve zero imbalances is unlikely even among loosely-blocked randomized controlled trials and perfect one-to-one matching is known to be rarely feasible in real data (King and Nelson, 2016), propensity score matching beginning with the estimation of a logistic regression model is more susceptible to the propensity paradox and the selection of random distal matches than contemporary extensions of propensity score matching strategies (e.g., Mahalanobis distance matching and coarsened exact matching; King and Nielsen, 2016; Nielsen, forthcoming). 
While it is important to acknowledge the limitations of any matching strategy and recognize the slow movement toward alternative extensions that are also not without criticism (see Gaes, Bales, and Scaggs, Forthcoming; Iacus, King, and Porro, 2012; Stuart, 2010), propensity score matching does produce adequate counterfactuals when the procedure is carefully constructed. At best, propensity score matching parallels a completely randomized experimental design (King and Nielsen, 2016). Most randomized controlled trials in the field of criminology and criminology follow this design; few are able to achieve the ideal fully blocked randomized controlled trial where zero imbalances can be assumed by design (Ariel and Farrington, 2010). At worst, propensity score matching adds little more to the estimation of a treatment effect than a propensity adjusted regression model (Apel and Sweeten, 2010). The determination of where any one propensity score matching strategy falls on the continuum of methodological rigor is contingent upon a series of diagnostic checks. Often these verifications are withheld from publications, which leads to unanswered questions about the quality of the matching procedure that had been conducted. To lift the veil of secrecy that is often attributed to matching procedures and provide transparency a series of checks were administered.

First, concerns about the quality and quantity of pretreatment covariates used to create the propensity score must be addressed. The main issue here is the proverbial question of whether apples to apples or apples to oranges comparisons are being made. Different preferences are used to accomplish the first step in the matching process, ranging from the use of theoretically informed logistic regression model specifications to a "kitchen sink" model of any and all covariates that are available to a researcher (Apel and Sweeten, 2010). Our scores were generated under the auspices of the latter perspective. 
Specifically, the choice of measures to include in the specification of the propensity score were informed by existing literature on the differences between convicted sex offenders and nonsex offenders, and known legal and extra-legal correlates influencing conviction and sentencing decisions. For instance, individuals convicted of sex offenses tend to be older and less racially heterogeneous (Amirault and Beauregard, 2014; Greenfield, 1997; Fazel, Hope, O’Donnell and Jacoby, 2002; Pennsylvania Commission on Sentencing, n.d.), have different profiles of social capital resources (e.g., educational attainment and marital status) (Greenfield, 1997; Fazel et al., 2002), and less extensive criminal histories (Hilinski-Rosick, Freiburger, and Verheek, 2014; Pennsylvania Commission on Sentencing, n.d.). To this extent, we sought to incorporate measures which captured variation in demographic characteristics (age, sex, and race), social capital resources (marital status and educational attainment), and criminal history (prior convictions and commitments). All variables included in the propensity score estimation for offenders from each state are included in Table A1. In all, 12 (Missouri) to 21 (Michigan) covariates were used, which is not necessarily a large quantity of potential confounders but is also not a small quantity (see Apel and Sweeten, 2010).

The specification of the propensity score model is an important decision in the estimation of treatment effects, as alternative specifications can result in different estimates of the effect (Smith and Todd, 2005). In the present case, several restrictions were imposed on the measures available for matching. First, the measures available for the matching algorithm were necessarily structured by the data available from the Michigan and Missouri Departments of Correction. This entailed that certain measures were available for one state but not necessarily for the other, as it was possible to use additional detail and indicators for Michigan parolees over and above Missouri parolees. This was primarily true of criminal history indicators, as Michigan 
systematically collects data on juvenile justice contacts, while Missouri was not available to make these data available.

Second, because selection to sex offender status was utilized as the treatment, only covariates which occurred temporally prior to entry into the treatment group could be used in the match, which necessarily limited the possible covariates to include. For instance, indicators relevant recidivism which also varied significantly across sex and non-sex offenders were available, and included incarceration length (Meade, Steiner, Makarios, and Travis, 2013), recidivism risk assessments (Thornton et al., 2006), and institutional misconduct (Steiner, Butler, and Ellison, 2014). However, variation in these factors may be a result of sex offender status, which makes them inappropriate for inclusion in a model designed to predict treatment status. This approach avoids using a procedure that would attempt to predict group membership based on covariates that were direct outcomes of that group membership (DeLisi, Barnes, Beaver, and Gibson, 2009; Rengifo and Stemen, 2013).

Third, propensity score based methods attempt to achieve covariate balance between treated and untreated units on the basis of observed covariates, leaving the possibility that unobserved covariates may remain unbalanced across groups (Morgan and Harding, 2006). Even if covariate balance is achieved on observed covariates, "hidden biases" stemming from the omitted covariates may encroach on the estimation of treatment effects (Heckman and Robb, 1985). Because the current inquiry relies on official record data in order to obtain observed covariates, this is a pertinent concern for the matched samples utilized here (Smith and Todd, 2005). In the ideal scenario, additional covariates from sources other than administrative or official records would have been available to add additional strength to model selection into sex offender treatment status. For instance, a robust predictor of sexual offending that was not 
available for matching is a history of sexual abuse (Jespersen, Lalumière, and Seto, 2009). While it is possible that this information may have been available for some offenders when the simulated treatment assignment was determined via a pre-sentence investigation report, it is unlikely that this information would have been systematically available across the samples. Although the impact of these hidden biases cannot be directly assessed, in the next section we utilize a sensitivity check forwarded in recent criminological work (Loughran, Wilson, Nagin, and Piquero, 2015).

An additional concern is that once the propensity score matching was complete, balance was assessed, and the data request to the Michigan and Missouri Departments of Correction were made, not all of the identified offenders had valid address data. As a consequence, even if balance were achieved on the matched samples, the offenders with valid address data may no longer be balanced on observed covariates. The next section details covariate balance and sensitivity checks for the parolees for which valid address data could be obtained, or 1,930 Michigan sex offenders and 1,917 Michigan Non-sex offenders, and 1,665 Missouri sex offenders and 1,816 Missouri non-sex offenders. The SORR violation rates estimated in the manuscript were based on these cohorts of offenders.

Covariate Balance and Sensitivity

Matching was performed using the psmatch2 function in Stata, utilizing a logit distance metric, a one-to-one nearest neighbor match, and a caliper of 0.001 . The choice of a caliper is an arbitrary one (Peters, Hochstetler, DeLisi, and Kuo, 2015), but due to the large number of potential comparisons in the non-sex offender samples we opted to use a tight caliper to obtain a relatively close match. Additionally, the matching was stratified by county urbanicity (i.e., rural, 
urban, metropolitan) so that sex offenders released to certain counties were similar to non-sex offenders released to similar counties. Matched samples were restricted to common support to ensure the representation of propensity scores across treatment and control groups. Considerable overlap in disaggregated scores across sex and non-sex offenders was obtained (see Figure A1). Covariate balance across sex and non-sex offenders was assessed using the standard difference, calculated using Equation A1 for continuous covariates, and Equation A2 for categorical covariates,

$$
d=\frac{\left(\bar{x}_{t}-\bar{x}_{c}\right)}{\sqrt{\frac{s_{t}^{2}+s_{c}^{2}}{2}}}
$$

$$
d=\frac{\left(\hat{p}_{t}-\hat{p}_{c}\right)}{\sqrt{\frac{\hat{p}_{t}\left(1-\hat{p}_{t}\right)+\hat{p}_{c}\left(1-\hat{p}_{c}\right)}{2}}}
$$

Where the means and variances for the treatment (sex offenders) and control (non-sex offenders) groups are represented by $\bar{x}_{t}, \bar{x}_{c}, s_{t}^{2}$ and $s_{c}^{2}$, and $\hat{p}_{t}$ and $\hat{p}_{c}$ represent the prevalence (mean) of a binary categorical covariate for the treatment and control groups. Consistent with previous literature, we consider a standard difference less than 0.1 to suggest negligible differences between groups, and greater than 0.2 as the threshold for imbalance (Austin, 2011; Loughran et al., 2015). Covariate balance was retained for both states, with an average standard difference of 0.078 in Michigan and 0.046 in Missouri. In Michigan, the adult probation term approached imbalance $(d=0.191)$, and prior misdemeanor conviction $(d=0.217)$ was above the imbalance threshold.

It is helpful to put this degree of covariate balance in perspective by comparing them to the same standard difference statistics computed for the unmatched offenders. This check suggested that in the aggregate the matched Michigan sample has $84 \%$ less covariate imbalance on average, while the Missouri sample has $62 \%$ less. The unmatched offenders more closely 
resembled non-sex offenders, in that they were younger, more racially heterogeneous, and had a more extensive criminal history than the matched offenders in each state.

While there is evidence that selection into sex offender and non-sex offender groups was equivalent by observable characteristics, it is not possible to completely rule out the possible existence of unobserved imbalances. As noted, the use of administrative data from state Departments of Correction limited the covariates available for matching, increasing the possibility of unobserved covariates potentially biasing the estimation of treatment effects. The unconfoundedness assumption holds that treatment statuses should also be equivalent on unobserved covariates (Loughran et al., 2015). This assumption is problematic for any matching strategy as it is fundamentally untestable. The assumption is particularly relevant for the current research given the effort to match sex offenders to non-sex offenders and the reliance on administrative data. Theoretically, all or a subset of covariates used to achieve balance between groups that are associated with unobserved covariates will satisfy the unconfoundedness assumption (see King and Nielsen, 2016).

Recently, Loughran and colleagues (2015) suggested the use of Rosenbaum's (2002) critical Gamma $(\Gamma)$ statistic to assess the sensitivity of treatment effect estimates to potential hidden biases. For a given treatment effect, $\Gamma$ represents the effect of an unobserved covariate which is predictive of the outcome (Keele, 2011). As a robustness check to a propensity scorebased treatment effect, $\Gamma$ suggests how strong hidden biases would need to be in order to "break" the significance of the effect. A $\Gamma=1.00$ means that the findings only hold when there are no hidden biases, while a $\Gamma=2.00$ indicates that findings would hold even if the treatment group were twice as likely to experience the outcome due to an unobserved covariate (Loughran et al., 2015). A $\Gamma$ of 1.30 is suggested as a threshold to indicate that a given treatment effect is sensitive 
to hidden biases (Rosenbaum, 2005), while $\Gamma=1.50$ is a reasonable benchmark for social science applications (Keele, 2011).

Across each state, we estimate two critical $\Gamma$ values using the binarysens function in the R package rbounds (Keele, 2014). Because of the focus of the current inquiry on SORR violations, the critical $\Gamma$ refers to the estimated effect of sex offender status on the initial release address being within a SORR buffer zone. For both Michigan and Missouri, the critical $\Gamma$ value was quite small, with $\Gamma=1.10$ for Michigan and $\Gamma=1.11$ for Missouri, indicating that the estimated treatment effect is rather sensitive to potentially omitted variables. However, as can be observed in Table 3 in the manuscript and in the distribution of county-level violation rates (Figure B1 in the Appendix), the differences in SORR violations between sex and non-sex offender cohorts are already quite small, and small treatment effects are necessarily sensitive (Loughran et al., 2015). As variation in SORR violations between offender groups has been subject to little empirical attention, it is unknown whether such small, sensitive effect sizes are out of the ordinary.

As a point of comparison, recall the original purpose of the broader evaluation from which the current data were drawn was to utilize recidivism as an outcome. We computed the critical $\Gamma$ for the difference in technical violations between the sex and non-sex offender samples. A $\Gamma=1.65$ was obtained for Michigan and $\Gamma=1.23$ for Missouri, suggesting that the Missouri sample may be more sensitive to hidden biases. As this inquiry is the first to compare SORR violations across multiple cohorts of offenders, future research will be able to determine whether the omission of particular covariates is responsible for some of the observed differences between sex and non-sex offenders. 
Second, the procedure for generating matches must be diagnosed. Issues here involve congruence in the distance between matched pairs and model dependence, which both introduce unaccounted uncertainty and bias (King and Nielsen, 2016). We cannot completely rule out the potential influence of the former as propensity score matching violates the congruence principle by projecting covariates instead of allowing covariates to operate in the space they were created (see Iacus et al., 2011). The latter issue is also relevant to this and any study using matching strategies. Model dependence corresponds to the choice of the matching procedure used. In other words, model dependence is introduced when researchers choose to estimate matches with a particular technique among a host of alternatives (King and Nielsen, 2016). This limitation is similar to a mono-method threat to construct validity (Shadish, Cook, and Campbell, 2002), in which the use of a singular method becomes part of the definition of a given construct. As previously noted, our matching method is model dependent in that only one matching procedure was used, rather than comparing across multiple alternatives (e.g., Gaes et al., Forthcoming). In an effort to minimize the effects of both of these issues a number of techniques were employed. From the outset, we chose to use a tight caliper of 0.001 to obtain a relatively close match of sex offenders to non-sex offenders as the matching of these two groups is uncommon. The use of a restrictive caliper may increase imbalance (King and Nielsen, 2016), but as previously demonstrated we did not find this to be the case. We did not use the estimated outcomes (i.e., residence restriction violations) to guide our caliper choice (see Rubin, 2008), thus limiting researcher-induced model dependence bias (see King and Nielsen, 2016). Fortunately two states were used in this research, which allows us to examine whether our matching technique produces similar outcome prediction and thus minimizing some model dependence issues. As evidenced in Table 3 of the manuscript, and Figure B1 of Appendix B, in 
each state a small difference was observed between the aggregate violation rates for sex and nonsex offenders. That is, deploying a particular matching strategy in two separate states provided a built-in comparison producing substantively similar results, suggesting that the findings are not subject to model dependence. We acknowledge a necessary trade-off between reduced bias in the estimated treatment effect and the cost of increased variance with our matching strategy (Heckman et al., 1997). Based upon a simulation of different caliper specifications with one-toone nearest neighbor matching, the opposite may also hold true (Apel and Sweeten, 2010). A 0.001 caliper may produce a slightly higher treatment effect and lower standard error in relation to less restrictive calipers. Future replications are needed integrating recent extensions of matching techniques to determine the reliability of our estimated effects. 
Table A1. Covariate Balance and Match Quality in Michigan and Missouri Sex Offender and Non-Sex Offender samples

\begin{tabular}{|c|c|c|c|c|c|c|}
\hline \multirow[b]{2}{*}{ Demographics } & \multicolumn{3}{|c|}{ Michigan } & \multicolumn{3}{|c|}{ Missouri } \\
\hline & $\mathrm{SO}$ & NSO & Std. D. & $\mathrm{SO}$ & $\mathrm{NSO}$ & Std. D. \\
\hline Age (years) & 36.754 & 35.332 & 0.130 & 39.872 & 40.131 & 0.025 \\
\hline Female & 0.036 & 0.038 & 0.014 & 0.139 & 0.132 & 0.027 \\
\hline Non-White & 0.315 & 0.298 & 0.049 & 0.241 & 0.253 & 0.039 \\
\hline Single at Arrest & 0.541 & 0.550 & 0.024 & 0.469 & 0.487 & 0.050 \\
\hline Married at Arrest & 0.205 & 0.180 & 0.089 & 0.250 & 0.233 & 0.056 \\
\hline Div. / Wid. / Sep. & 0.254 & 0.270 & 0.053 & 0.279 & 0.280 & 0.001 \\
\hline Less than HS Diploma & 0.620 & 0.628 & 0.022 & -- & -- & -- \\
\hline HS Diploma & 0.294 & 0.282 & 0.038 & 0.637 & 0.662 & 0.075 \\
\hline More than HS & 0.086 & 0.091 & 0.023 & -- & -- & -- \\
\hline \multicolumn{7}{|l|}{ Criminal History } \\
\hline Juvenile Commitment & 0.049 & 0.058 & 0.058 & -- & -- & -- \\
\hline Juvenile Probation & 0.080 & 0.101 & 0.103 & -- & -- & -- \\
\hline Juvenile Escape & 0.008 & 0.008 & 0.001 & -- & -- & -- \\
\hline Adult Jail Term & 0.190 & 0.240 & 0.172 & -- & -- & -- \\
\hline Adult Probation & 0.208 & 0.266 & 0.191 & -- & -- & -- \\
\hline Adult Prison Term & 0.177 & 0.163 & 0.052 & -- & -- & -- \\
\hline Adult Escape & 0.009 & 0.016 & 0.081 & -- & -- & -- \\
\hline Prior Convictions & 0.627 & 0.815 & 0.155 & 1.897 & 1.938 & 0.047 \\
\hline Prior Felony & 0.196 & 0.235 & 0.132 & 0.923 & 0.945 & 0.128 \\
\hline Prior Misdemeanor & 0.198 & 0.263 & 0.217 & -- & -- & -- \\
\hline \multicolumn{7}{|l|}{ Strata } \\
\hline Rural County & 0.318 & 0.303 & 0.048 & 0.347 & 0.344 & 0.011 \\
\hline Urban County & 0.384 & 0.381 & 0.009 & 0.300 & 0.318 & 0.055 \\
\hline Metro County & 0.298 & 0.317 & 0.057 & 0.353 & 0.388 & 0.043 \\
\hline \multicolumn{7}{|l|}{ Critical Gamma $(\Gamma)$} \\
\hline SORR Violation & & 1.10 & & & 1.11 & \\
\hline Technical Violation & & 1.65 & & & 1.23 & \\
\hline $\mathrm{N}$ & 1,930 & 1,917 & & 1,665 & 1,816 & \\
\hline
\end{tabular}

Note: $\mathrm{SO}=$ Sex Offender; NSO = Non-Sex Offender; Std. D. = Standardized Difference; SORR $=$ Sex Offender Residence Restriction. 
Figure A1. Propensity Score Distributions across Matched Michigan and Missouri Samples

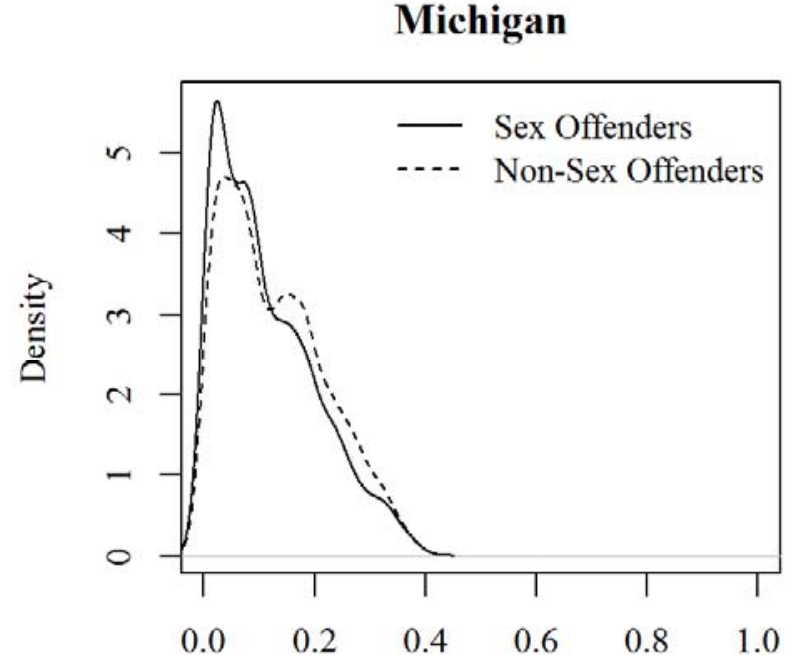

Probability of Treatment Assignment
Missouri

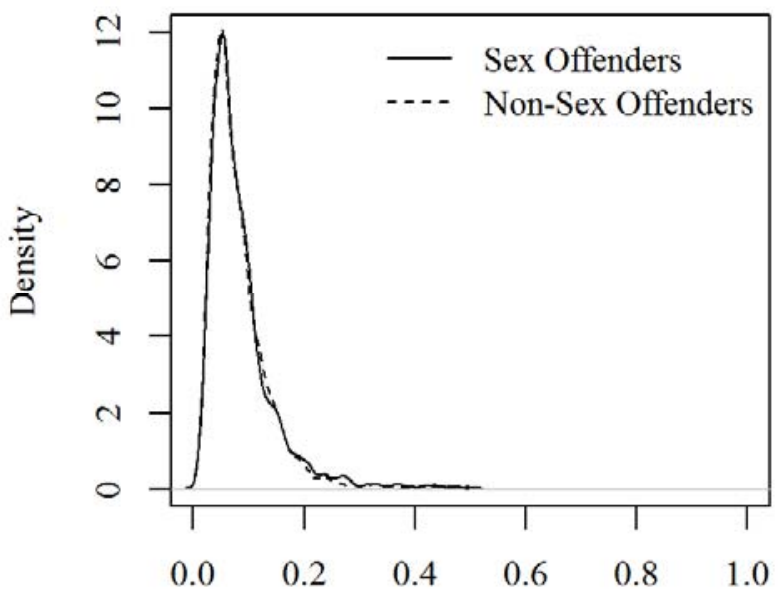

Probability of Treatment Assignment 


\section{Appendix B. Sex Offender Residence Restriction Violation Rate Distributions}

\section{Figure B1. County-Level Violation Rate Distributions by State and Cohort}

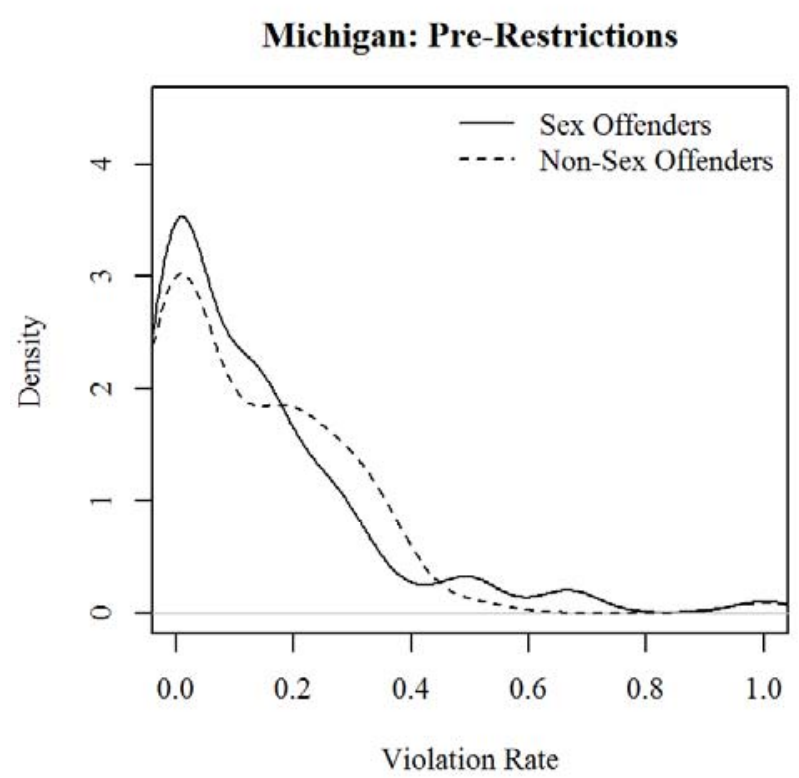

Michigan: Post-Restrictions

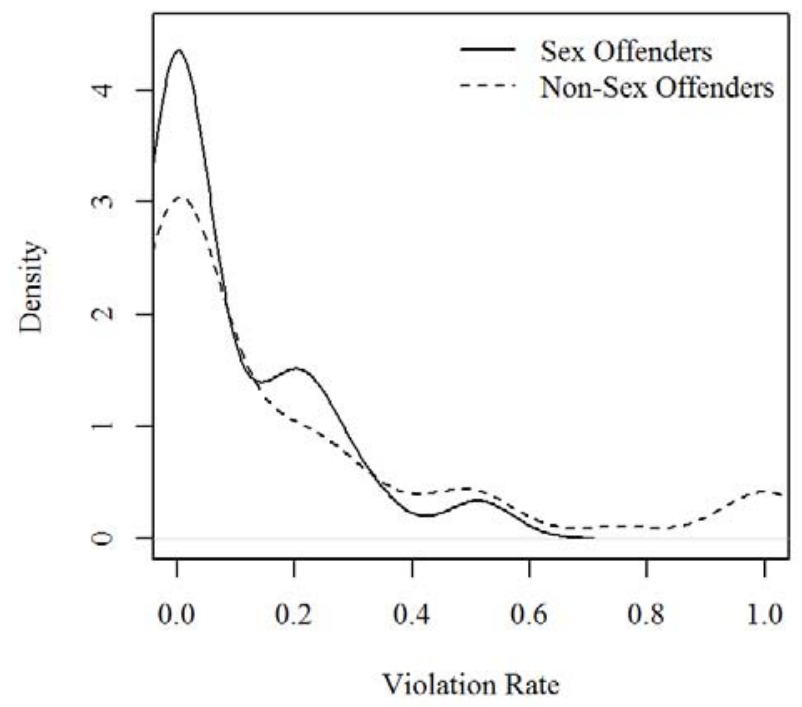

Missouri: Pre-Restrictions

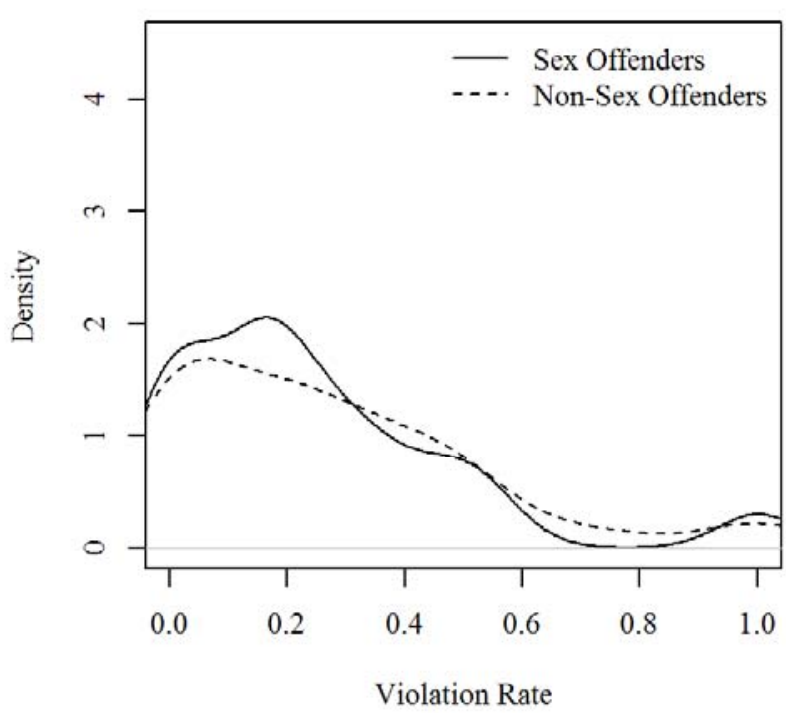

Missouri: Post-Restrictions

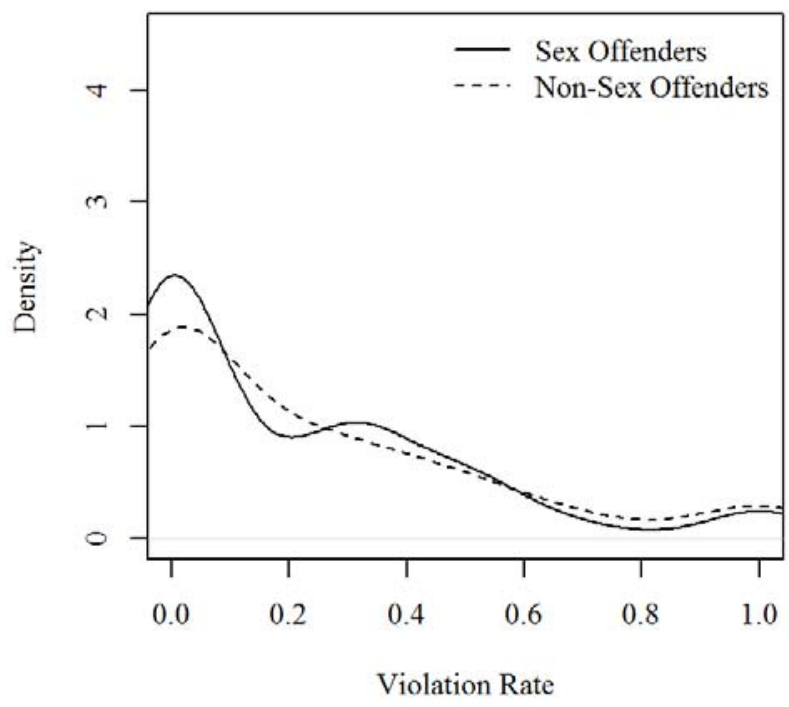




\section{Appendix C. Testing Equality of Effects across Cohorts}

In Table 4 we estimate fractional logit regression models to examine the social ecological factors associated with variation in county-level violation rates for the four cohorts - pre-SORR sex offenders, post-SORR sex offenders, pre-SORR non-sex offenders, and post-SORR non-sex offenders. Based on research indicating that the implementation of residence restrictions will impact the housing patterns of sex offenders (Levenson and Cotter, 2005; Rydberg, Grommon, Huebner, and Bynum, 2014; Socia, 2011), as well as research suggesting that sex offender housing patterns are distinct from those of non-sex offenders (Chajewski and Mercado, 2008; Walker et al., 2001), we estimate a series of models to test whether the effects in Table 4 are consistent across cohorts.

We utilize the following approach to estimate if there are statistical differences in the effect of variables across cohorts. The dataset of county covariates $(\mathrm{N}=198)$ are first stacked one on top of the other to create a pooled dataset $(\mathrm{N}=396)$. A series of vectors are then created to allow for particular cohort comparisons. For instance, the pre-SORR sex offender and postSORR sex offender violation rates are stacked to a single column vector and appended to the county covariates to compare sex offender violation rates across restriction periods. The postSORR non-sex offender and post-SORR sex offender violation rates are stacked to compare sex and non-sex offenders during a particular restriction period. A difference indicator (D) is then appended to the stacked data, which is equal to 0 for the first 198 values, and 1 for the next 198. This measure is used to indicate differences between sex offenders and non-sex offenders or preand post-SORR periods (depending on the outcome of interest). We then estimate re-estimate the regression models specified in Table 4, with an additional 13 regressors comprising the interaction between D (i.e., either Post-SORR vs. Pre-SORR, or Sex Offender vs. Non-Sex 
Offender) and each covariate in the model. The test statistics and p-values for the interaction terms represent a test of a difference between the covariate effects either across offender groups or restriction periods (Hoekter, 2007; Williams, 2009).

Four comparisons are estimated and included in Table C2. The first two models compare differences in effects across pre- and post-SORR periods for both sex offenders (Model C1) and non-sex offenders (Model C2). An inspection of the interaction effects indicates that there were no significant differences in effects between the restriction periods, with the exception of criminal justice system resources for sex offenders $(E s t=-0.30, S E=0.14, z=-2.12, p=0.034)$, suggesting that the association between criminal justice system resources and sex offender violation rates was significantly smaller during the post-SORR period. Comparing sex and nonsex offenders within restriction periods (Models C3 and C4) yielded two significant differences. The association between unemployment and violation rates were significantly smaller for sex offenders than non-sex offenders during both the pre-SORR $(\mathrm{Est}=-0.47, \mathrm{SE}=0.22, \mathrm{z}=-2.10, \mathrm{p}$ $=0.035)$ and post-SORR periods (Est $=-1.26, \mathrm{SE}=0.41, \mathrm{z}=-3.08, \mathrm{p}=0.002)$. We also observe that during the post-SORR period the effect of concentrated disadvantage is significantly larger for sex offenders than non-sex offenders ( $E s t=0.42, \mathrm{SE}=0.18, \mathrm{z}=2.30, \mathrm{p}=0.022$ ). 
Table C1. Fractional Logit Regression Models of SORR Violation Rates on County-Level Variables, Pooled Data to Test Equality of Effects $(\mathbf{N}=396)$

\begin{tabular}{|c|c|c|c|c|}
\hline \multirow{2}{*}{$\begin{array}{l}\text { Comparison (D) } \rightarrow \\
\text { Model Subset } \rightarrow\end{array}$} & \multicolumn{2}{|c|}{ Pre- vs. Post-SORR } & \multicolumn{2}{|c|}{ Non-Sex vs. Sex Offenders } \\
\hline & SOs & NSOs & Pre-SORR & Post-SORR \\
\hline & Model C1 & Model C2 & Model C3 & Model C4 \\
\hline Independent Variables $\downarrow$ & $\beta(\mathrm{SE})$ & $\beta(\mathrm{SE})$ & $\beta(\mathrm{SE})$ & $\beta(\mathrm{SE})$ \\
\hline Intercept & $-3.30(0.81)^{* * *}$ & $-2.13(0.75)^{* * *}$ & $-2.13(0.75)^{* *}$ & $0.33(1.22)$ \\
\hline Housing Availability ${ }^{\mathrm{a}}$ & $0.09(0.10)$ & $0.18(0.10)$ & $0.18(0.10)$ & $0.08(0.18)$ \\
\hline Housing Affordability ${ }^{\mathrm{b}}$ & $-0.32(0.27)$ & $0.04(0.26)$ & $0.04(0.26)$ & $0.10(0.44)$ \\
\hline Unemployment Rate ${ }^{\mathrm{b}}$ & $-0.30(0.17)$ & $0.16(0.15)$ & $0.16(0.15)$ & $0.64(0.25)^{*}$ \\
\hline Residential Instability & $-0.09(0.10)$ & $-0.01(0.09)$ & $-0.01(0.09)$ & $-0.08(0.16)$ \\
\hline Racial/Ethnic Heterogeneity & $-0.06(0.08)$ & $0.12(0.13)$ & $0.12(0.13)$ & $0.05(0.21)$ \\
\hline Concentrated Disadvantage & $0.14(0.08)$ & $-0.01(0.08)$ & $-0.01(0.08)$ & $-0.05(0.13)$ \\
\hline SORR Density & $0.68(0.16)^{* * *}$ & $0.47(0.10)^{* *}$ & $0.47(0.15)^{* *}$ & $0.55(0.23)^{*}$ \\
\hline CJ System Resources & $0.25(0.07)^{*}$ & $0.29(0.07) * * *$ & $0.29(0.07)^{* * *}$ & $0.26(0.12)^{*}$ \\
\hline Cohort Flow $^{\mathrm{b}}$ & $0.21(0.10)^{*}$ & $0.01(0.10)$ & $0.01(0.10)$ & $0.19(0.14)$ \\
\hline Urbanity & $0.00(0.04)$ & $-0.02(0.04)$ & $-0.02(0.04)$ & $-0.09(0.07)$ \\
\hline Missouri & $0.97(0.16)^{* * *}$ & $0.68(0.16)^{* * *}$ & $0.68(0.16)^{* * *}$ & $1.14(0.25)^{* * *}$ \\
\hline Spatial Lag & $0.05(0.61)$ & $1.29(0.50)^{* *}$ & $1.29(0.50)^{* *}$ & $-0.46(0.73)$ \\
\hline $\mathrm{D}$ & $-0.87(1.60)$ & $2.46(1.43)$ & $1.17(1.10)$ & $-4.50(1.84)$ \\
\hline $\mathrm{D} \times$ Housing Availability $^{\mathrm{a}}$ & $-0.01(0.20)$ & $-0.10(0.20)$ & $-0.09(0.14)$ & $0.00(0.25)$ \\
\hline $\mathrm{D} \times$ Housing Affordability $^{\mathrm{b}}$ & $-0.41(0.55)$ & $0.06(0.51)$ & $-0.36(0.38)$ & $-0.83(0.65)$ \\
\hline $\mathrm{D} \times$ Unemployment Rate $^{\mathrm{b}}$ & $-0.32(0.37)$ & $0.47(0.29)$ & $-0.47(0.22)^{*}$ & $-1.26(0.41)^{* *}$ \\
\hline $\mathrm{D} \times$ Residential Instability & $0.32(0.18)$ & $-0.07(0.18)$ & $-0.07(0.14)$ & $0.31(0.22)$ \\
\hline $\mathrm{D} \times$ Racial/Ethnic Het. & $0.31(0.25)$ & $-0.07(0.25)$ & $-0.18(0.19)$ & $0.20(0.29)$ \\
\hline $\mathrm{D} \times$ Conc. Disadvantage & $0.24(0.16)$ & $-0.03(0.15)$ & $0.16(0.11)$ & $0.42(0.18)^{*}$ \\
\hline $\mathrm{D} \times$ SORR Density & $-0.09(0.29)$ & $0.09(0.28)$ & $0.21(0.22)$ & $0.03(0.34)$ \\
\hline $\mathrm{D} \times \mathrm{CJ}$ System Resources & $-0.30(0.14)^{*}$ & $-0.03(0.14)$ & $-0.03(0.10)$ & $-0.30(0.17)$ \\
\hline $\mathrm{D} \times$ Cohort Flow $^{\mathrm{b}}$ & $-0.13(0.17)$ & $0.18(0.17)$ & $0.20(0.14)$ & $-0.11(0.20)$ \\
\hline $\mathrm{D} \times$ Urbanity & $0.04(0.08)$ & $-0.07(0.08)$ & $0.02(0.06)$ & $0.13(0.10)$ \\
\hline $\mathrm{D} \times$ Missouri & $-0.18(0.31)$ & $0.46(0.30)$ & $0.29(0.22)$ & $-0.36(0.37)$ \\
\hline $\mathrm{D} \times$ Spatial Lag & $0.56(0.99)$ & $-1.74(0.89)^{*}$ & $-1.24(0.79)$ & $1.06(1.07)$ \\
\hline
\end{tabular}

Note: ${ }^{*} \mathrm{p}<.05 ; * * \mathrm{p}<.01 ; * * * \mathrm{p}<.001 ; \mathrm{SO}=$ Sex offenders; NSO = Non-Sex Offender; SORR $=$ Sex Offender Residence Restrictions

D: In the Pre/Post comparison, D indicates Post-Restriction = 1; In the Sex/Non-Sex Offender comparison, D indicates Sex Offender $=1$

${ }^{a}$ Indicates that the predictor has been standardized.

${ }^{\mathrm{b}}$ Indicates that the predictor has been logged. 


\section{References Found in Appendices}

Amirault, J., and Beauregard, E. (2014). The impact of aggravating and mitigating factors on the sentence severity of sex offenders: An exploration and comparison of differences between offending groups. Criminal Justice Policy Review, 25(1), 78-104.

Apel, R. J. and Sweeten, G. (2010). Propensity score matching in criminology and criminal justice. In A. R. Piquero and D. Weisburd (Eds.), Handbook of quantitative criminology (pp. 543-652). New York, NY: Springer.

Ariel, B., and Farrington, D. P. (2010). Randomized block designs. In A. R. Piquero and D. Weisburd (Eds.), Handbook of quantitative criminology (pp. 437-454). Springer New York.

Austin, P. C. (2011). An introduction to propensity score methods for reducing the effects of confounding in observational studies. Multivariate Behavioral Research, 46(3), 399-424.

Craig, L. A., Browne, K. D., Beech, A., and Stringer, I. A. N. (2006). Differences in personality and risk characteristics in sex, violent and general offenders. Criminal Behavior and Mental Health, 16(3), 183-194.

DeLisi, M., Barnes, J. C., Beaver, K. M., and Gibson, C. L. (2009). Delinquent gangs and adolescent victimization revisited: A propensity score matching approach. Criminal Justice and Behavior, 36(8), 808-823.

Fazel, S., Hope, T., O’Donnell, I., and Jacoby, R. (2002). Psychiatric, demographic and personality characteristics of elderly sex offenders. Psychological Medicine, 32(2), 219226.

Gaes, G. G., Bales, W. D., and Scaggs, S. J. A. (Forthcoming). The effect of imprisonment on recommitment: An analysis using exact, coarsened exact, and radius matching with the propensity score. Journal of Experimental Criminology, DOI: 10.1007/s11292-015-9251$\mathrm{x}$

Gendreau, P., Little, T., and Goggin, C. (1996). A meta-analysis of the predictors of adult offender recidivism: What works! Criminology, 34(4), 575-608.

Greenfield, L. A. (1997). Sex offenses and offenders: An analysis of data on rape and sexual assault. Washington D.C.: U.S. Department of Justice: Bureau of Justice Statistics.

Gu, X. S. and Rosenbaum, P. R. (1993). Comparison of multivariate matching methods: Structures, distances, and algorithms. Journal of Computational and Graphical Statistics, $2(4), 405-420$. 
Heckman, J., Ichimura, H., and Todd, P. (1997). Matching as an econometric evaluator estimator: Evidence from evaluating a job training program. The Review of Economic Studies, 64(4), 605-654.

Heckman, J. J., and Robb, R., Jr. (1985). Alternative methods for evaluating the impact of interventions: An overview. Journal of Econometrics, 30(1), 239-267.

Hilinski-Rosick, C. M., Freiburger, T. L., and Verheek, A. (2014). The effects of legal and extralegal variables on the sentences of sex offenders. Victims and Offenders, 9(3), 334351.

Hoetker, G. (2007). The use of logit and probit models in strategic management research: Critical issues. Strategic Management Journal, 28(4), 331-343.

Huebner, B. M., Kras, K. R., Rydberg, J., Bynum, T. S., Grommon, E., and Pleggenkuhle, B. (2014). The effect and implications of sex offender residence restrictions. Criminology and Public Policy, 13(1), 139-168.

Iacus, S. M., King, G., and Porro, G. (2012). Causal inference without balance checking: Coarsened exact matching. Political Analysis, 20(1), 1-24.

Jespersen, A. F., Lalumière, M. L., and Seto, M. C. (2009). Sexual abuse history among adult sex offenders and non-sex offenders: A meta-analysis. Child Abuse and Neglect, 33(3), 179192.

Keele, L. J. (2011). Rbounds: An R package for Rosenbaum bounds sensitivity analysis with matched data. Ohio State University typescript.

Keele, L. J. (2014). rbounds: Perform Rosenbaum bounds sensitivity tests for matched and unmatched data. R package version 2.1. https://CRAN.R-project.org/package=rbounds

King, G. and Nielsen, R. (2016). Why propensity scores should not be used for matching. Unpublished manuscript, Institute for Quantitative Social Science, Harvard University, Cambridge, Massachusetts.

King, G., Nielsen, R., Coberley, C., and Pope, J. E. (2011). Comparative effectiveness of matching methods for causal inference. Unpublished manuscript, Institute for Quantitative Social Science, Harvard University, Cambridge, Massachusetts.

Langan, P. A., and Levin, D. A. (2002). Recidivism of prisoners released in 1994. Washington D.C.: U.S. Department of Justice: Bureau of Justice Statistics.

Langan, P. A., Schmitt, E. L., and Durose, M. R. (2003). Recidivism of sex offenders released from prison in 1994. Washington D.C.: U.S. Department of Justice: Bureau of Justice Statistics. 
Loughran, T. A., Wilson, T., Nagin, D. S., and Piquero, A. R. (2015). Evolutionary regression? Assessing the problem of hidden biases in criminal justice applications using propensity scores. Journal of Experimental Criminology, 11(4), 631-652.

Meade, B., Steiner, B., Makarios, M., and Travis, L. (2013). Estimating a Dose-response relationship between time served in prison and recidivism. Journal of Research in Crime and Delinquency, 50(4), 525-550.

Morgan, S. L., and Harding, D. J. (2006). Matching estimators of causal effects prospects and pitfalls in theory and practice. Sociological Methods and Research, 35(1), 3-60.

Nielsen, R. A. (Forthcoming). Case selection via matching. Sociological Methods and Research. DOI: $10.1177 / 0049124114547054$

Pennsylvania Commission on Sentencing. (n.d). Sentencing Guidelines Manuals. Retrieved from http://pcs.la.psu.edu/guidelines/sentencing/sentencing-guidelines-and-implementationmanuals

Peters, D. J., Hochstetler, A., DeLisi, M., and Kuo, H. J. (2015). Parolee recidivism and successful treatment completion: Comparing hazard models across propensity methods. Journal of Quantitative Criminology, 31(1), 149-181.

Rengifo, A. F., and Stemen, D. (2013). The impact of drug treatment on recidivism: Do mandatory programs matter? Evidence from Kansas' Senate Bill 123. Crime and Delinquency, 59(6), 930-950.

Rosenbaum, P. R. (2002). Observational studies. New York: Springer.

Rosenbaum, P. R. (2005). Sensitivity analysis in observational studies. In B. S. Everitt and D. C. Howell (eds.), Encyclopedia of Statistics in Behavioral Science (pp. 1809-1814). Chichester: John Wiley and Sons.

Rosenbaum, P. R. and Rubin, D. (1983). The central role of the propensity score in observational studies for causal effects. Biometrika, 70(1), 41-55.

Rubin, D. B. (2008). For objective causal inference, design trumps analysis. The Annals of Applied Statistics, 2(3), 808-840.

Rydberg, J., Grommon, E., Huebner, B. M., and Bynum, T. (2014). The effect of statewide residency restrictions on sex offender post-release housing mobility. Justice Quarterly, $31(2), 421-444$.

Sample, L. L., and Bray, T. M. (2003). Are sex offenders dangerous?. Criminology and Public Policy, 3(1), 59-82. 
Shadish, W. R., Cook, T. D., and Campbell, D. T. (2002). Experimental and quasi-experimental designs for generalized causal inference. Belmont, CA: Wadsworth Cengage.

Steiner, B., Butler, H. D., and Ellison, J. M. (2014). Causes and correlates of prison inmate misconduct: A systematic review of the evidence. Journal of Criminal Justice, 42(6), 462-470.

Stuart, E. A. (2010). Matching methods for causal inference: A review and a look forward. Statistical Science, 25(1), 1-21.

Thornton, D., Mann, R., Webster, S., Blud, L., Travers, R., Friendship, C., and Erikson, M. (2003). Distinguishing and combining risks for sexual and violent recidivism. Annals of the New York academy of sciences, 989(1), 225-235.

Williams, R. (2009). Using heterogeneous choice models to compare logit and probit coefficients across groups. Sociological Methods and Research, 37(4), 531-559. 


\section{ENDNOTES}

${ }^{i}$ This finding held for a hypothetical residence restriction policy of 1,000' of either limited, medium, or large scope. These differences were not present when the restriction buffer extended beyond 1,500'. The restriction buffers in the current inquiry are of limited scope (schools and day cares) with a 1,000' buffer.

ii A minimum match score of 60 was utilized. Overall, $79.5 \%$ of the addresses were matched with a score of 100 , $18.0 \%$ were matched with a score between 80 and 99.9 , and $2.5 \%$ were matched with a score between 60 and 80 . These match score thresholds are similar to those achieved by previous residence restriction studies (e.g., Zgoba et al., 2009).

iii Initially, the unemployment rate was included as a variable in the factor solution for concentrated disadvantage, as it was expected to load highly and has been utilized in in previous research (Hipp et al., 2010; Socia, 2011). However, the unemployment rate was not observed to load on the factor, and we found the solution fit (RMSEA) was substantially improved by removing the variable. Given the theoretical significance and historical salience of unemployment to the study sites, it was included separately in multivariate modeling, rather than being discarded altogether.

iv As it is calculated, SORR density captures the number of restricted objects for every 1,000 population. Given the spatial dimension of residence restrictions, an alternative would be to use the total county land area in square miles as the denominator. We elected to use total population as the denominator to correct for rural counties. That is, rural counties in the study states have fewer schools and day cares than more metropolitan counties, but these restricted objects also tended to be concentrated into small areas, such as the most populous town in the county. As such, a small number of well-placed restriction boundaries could eliminate a relatively large number of viable housing options, despite the large land area to schools/day cares ratio.

${ }^{\mathrm{v}}$ We explored several different operationalizations of this variable. Both binary (metropolitan vs. non-metropolitan) and ordinal (rural, urban, metropolitan) operationalizations made no difference in multivariate modeling.

${ }^{v i}$ OLS and Tobit regression cannot guarantee that fitted values fall within the unit interval (Wooldridge, 2002), potentially producing nonsensical predictions. Beta regression is an alternative, but can only handle dependent variable values falling between, and not on, 0 and 1 (Ferrari and Cribari-Neto, 2004).

${ }^{\text {vii }}$ As an alternative to the weighted logit model, fractional logit models can be estimated by utilizing a two column matrix of successes and trials (i.e., violations and total cohort members) as the dependent variable, instead of a vector of violation rates. Each produces identical estimates. Similarly, an alternative procedure would be to estimate a Poisson regression using the number of violation addresses as the dependent variable with the log of the total parolees to the county as an offset. This procedure produced substantively identical findings to the fractional logit regression.

viii These violation rates were based on very small numbers of released sex offenders (i.e., 1-3). Because of the small number of parolees in these counties, the fractional logit estimation gives higher importance to counties with larger parolee populations.

ix The county sample utilized in the estimation was smaller than the overall $\mathrm{N}$ since there were 48 counties which did not have any sex offenders released to them during the period, and thus were treated as missing (i.e., rather than having a violation rate of 0 ).

${ }^{\mathrm{x}}$ Multicollinearity diagnostics (i.e., $\sqrt{V I F}$ ) suggested no problematic values. Tests for model misspecification (RESET) suggested that model fit would not benefit from the addition of any polynomials of the predictors. xi Prior to the estimation of the full models we estimated a series of iterative models for each of the individual variable groupings (available upon request) on the post-SORR sex offender violation rate. Significant associations were observed for urban counties (+), Missouri counties (+), housing availability $(+)$, residential instability $(+)$, concentrated disadvantage $(+)$, and criminal justice system resources $(+)$. The environmental justice group produced the best model fit $(\mathrm{AIC}=290.20)$ and the highest variance explained $\left(\mathrm{R}^{2}=0.27\right)$. Concerning the sign change for criminal justice system resources between the iterative and full models, sensitivity analyses observed moderate correlation $(0.42-0.55)$ and explained variance $(0.18-0.30)$ between criminal justice system resources, residential instability, and racial/ethnic heterogeneity. Essentially, counties with more criminal justice system resources have higher residential instability and more racial/ethnic heterogeneity.

xii We would like to thank an anonymous reviewer for suggesting this approach.

xiii The simulated data has 5,000 observations. The predicted violation rates for the entire range of concentrated disadvantage across the entire range of restriction density, split into 50 equally spaced segments $(50 \times 50=2,500)$ for both Michigan and Missouri $(2,500 \times 2=5,000)$, while holding all other variables in the model constant at their mean value. 